\title{
Guidelineson
}

\section{National Inventory of Village Forests}

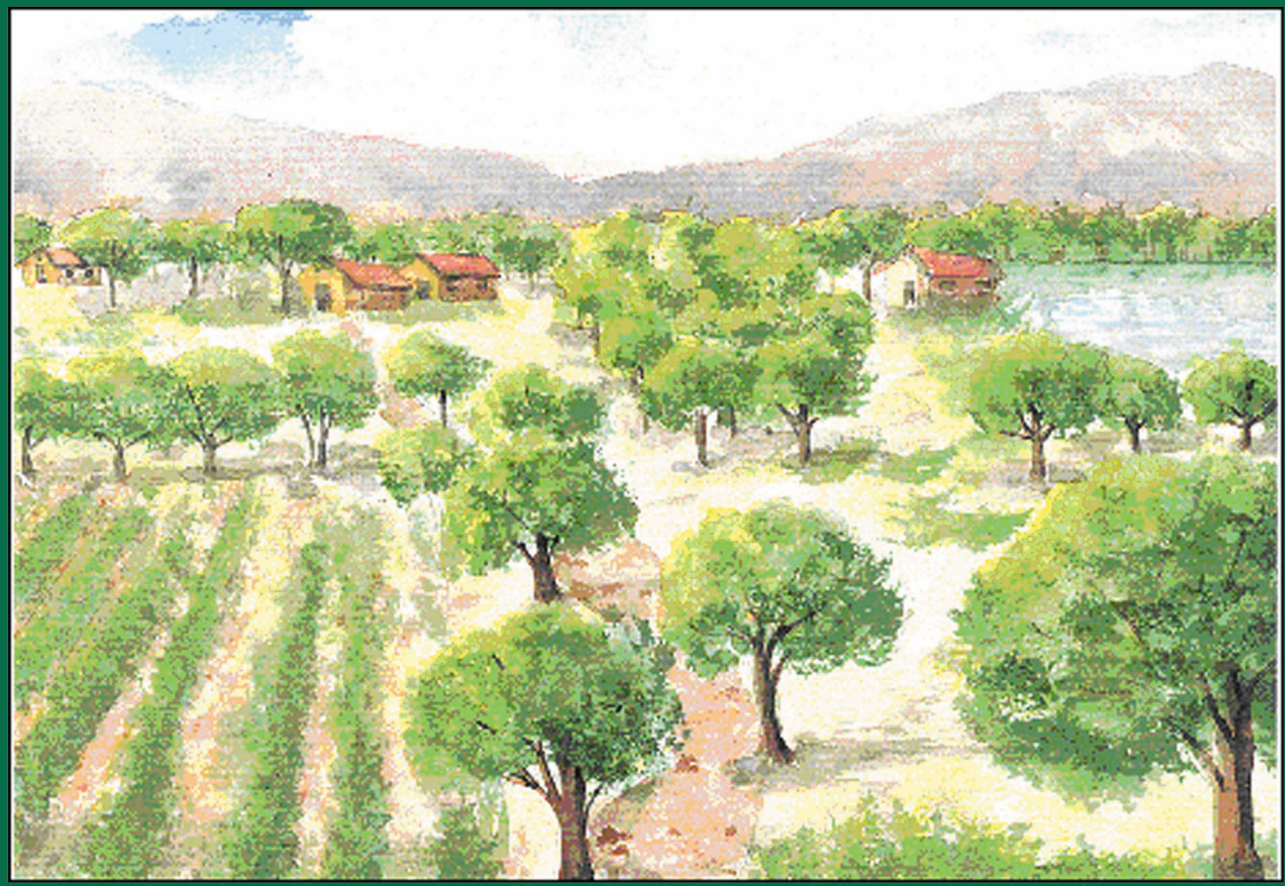

K.D. Singh 


\section{Guidelines on \\ National Inventory of Village Forests}

K.D. Singh
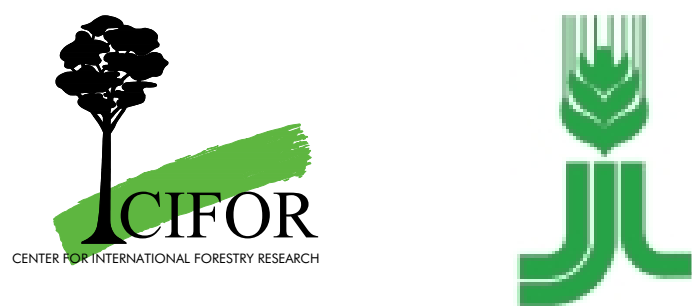


\section{Contents}

Abbreviations vi vi

Glossary vii

Preface viii

Abstract

1. Introduction 2

2. Problem formulation 5

2.1 Introduction 5

2.2 National forest inventory objectives 5

2.3 Emerging issues in setting inventory objectives 6

2.4 Problem formulation for a national inventory of village forests $\quad 7$

2.5 Examples of village forest inventories 8

3. Survey planning 10

$\begin{array}{lll}3.1 & \text { Introduction } & 10\end{array}$

3.2 Survey planning check list 11

3.3 Information need analysis: a matrix approach 13

3.4 Consistency between national inventories of village forests and
forest reserves

$\begin{array}{ll}3.5 & \text { Delineation of survey universe } \\ \end{array}$

4. Survey design 17

4.1 Introduction 17

4.2 Sampling frame, size and shape of sampling units 17

4.3 Sampling plan 18

4.4 Non-standard sampling procedures for village forest inventories $\quad 19$

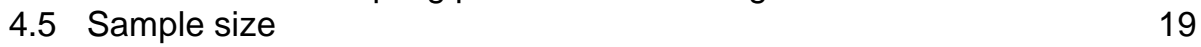

4.6 Subsampling and recording units 20

$\begin{array}{lll}4.7 & \text { Special studies } & 20\end{array}$

4.8 Examples of survey procedures 20

4.9 A complete case study: survey of trees and hedgerows in the

4.10 Sample survey check-list 23

5. Role of remote sensing 25

5.1 Introduction 25

5.2 Application of remote sensing 25

5.3 Integrating remote sensing and field surveys 26

5.4 Using satellite remote sensing to detect changes 27 
6. Field survey 29

6.1 Introduction 29

6.2 Field measurements 29

6.3 Maintaining quality control of fieldwork and data 31

6.4 Consistency checking and data archiving 31

7. Special studies 33

7.1 Introduction 33

7.2 Tree volume estimation 34

$\begin{array}{lll}7.3 & \text { Fodder yield study } & 35\end{array}$

$\begin{array}{lll}7.4 & \text { Fruit yield } & 35\end{array}$

7.5 Tree increment 36

7.6 Participatory and rapid rural appraisal techniques 36

8. Data processing 39

8.1 Introduction 39

8.2 Data processing algorithms 39

8.3 Computational phase in forest inventory 39

8.4 Database storage and archival routines 42

9. Survey evaluation $\quad 43$

9.1 Introduction 43

9.2 Survey methodology 43

9.3 Development aspects of the village forest inventory 44

$\begin{array}{ll}\text { Acknowledgements } & 46\end{array}$

$\begin{array}{ll}\text { References } & 47\end{array}$

Annex 1. Emerging technologies $\quad 50$

Introduction $\quad 50$

Geo-positioning systems $\quad 50$

Geographic information system $\quad 50$

Modeling 51

Annex 2. Institutional requirements $\quad 54$

Introduction $\quad 54$

Planning phase $\quad 54$

Implementation phase $\quad 54$

End phase $\quad 55$ 


\section{Tables}

Table 1. Main elements of the guidelines

Table 2. Differences between inventory of forest reserves and village forests

Table 3. Information needs and sources

Table 4. A hierarchic classification of land use and forest cover classes

Table 5. Change matrix at the Sampling Unit 4409 in Northeast India - Period covered: December 1981 - February 1988

Table 6. Assumptions made in the model regarding future state of the district

\section{Figures}

Figure 1. A landscape in Doon Valley of India showing alternating agriculture and trees

Figure 2. An example of a common land use and forest classification

Figure 3. Field form used in Bangladesh national inventory

Figure 4. Data processing flow chart used in many inventories in the tropics

Figure 5. Overview of a geographic information system 


\section{Abbreviations}

DBH Diameter at breast height

GIS Geographic Information System

GPS Geo-positioning Systems

FAO Food and Agriculture Organization of the United Nations

IPCC International Panel on Climate Change

IRS Indian Remote Sensing Satellite

MSS Multi-Spectral Scanner

NFI National Forest Inventory

VFI Village Forest Inventory

OB Over Bark

SR Simple Random Sampling

ST Stratified Random Sampling

RRA Rapid Rural Appraisals

SU Sampling Unit

TM Thematic Mapper

UB Under Bark 


\section{Glossary}

Agroforestry/agroforests: a collective term for systems of land use/land in which woody perennials (trees and shrubs) are intentionally maintained in association with crops and/or livestock; in agroforests there is both an ecological and an economic interaction between the tree and non-tree components.

Biomass: is the total above ground biomass of trees of $10 \mathrm{~cm}$ diameter (breast height) or larger, including main stems, branches, bark, twigs, leaves and fruits.

Forest: an area managed for the production of timber and other forest products and/or maintained under woody vegetation for indirect benefits such as protection of catchment areas or recreation. The forest may be natural or planted.

Forest fallow: all complexes of woody vegetation deriving from the clearing of natural forest for shifting agriculture. It consists of a mosaic of various succession phases and includes patches of uncleared forests and agriculture fields, which cannot be realistically segregated and accounted for area-wise, especially from satellite imagery.

Forest land: an area of land proclaimed to be forest under a forest act or ordinance

Interdependent interpretation: the visual interpretation of two satellite images of two different dates within a single interpretation process.

Multidate or multitemporal images: two or more satellite images of different dates and covering the same portion of earth's surface.

Other wooded lands: all land use categories bearing trees, very open forests less than $10 \%$ tree cover, forest fallow, etc

Shrubs: vegetation types where the dominant woody elements are shrubs with more than $50 \mathrm{~cm}$ and less than $5 \mathrm{~m}$ height on maturity.

Trees: woody perennials with a single main stem (except in coppice crops where multiple stems replace a single stem), a more or less definite crown and a minimum height of more than $5 \mathrm{~m}$ on maturity.

Village forests: all forms of woody vegetation growing in rural landscapes such as block plantations; orchards and groves; shelterbelts and windbreaks; canal and pond banks, rail and roadside plantations; homestead plantings; and trees in the agricultural fields (i.e. agroforests). It also includes natural forest and other wooded lands under village management, and shifting cultivation. 


\section{Preface}

The report presents guidelines on national inventory of trees and forests occurring in rural landscapes or village forests. In spite of the great importance to the local community, these resources have often been overlooked in the past by land management agencies. Reliable information about their contributions to the rural economy would help not only in raising awareness of policy makers but also getting the needed support for their management and development. CIFOR commissioned Dr. K.D. Singh, an inventory specialist identified by the donor for this activity (International Fund for Agricultural Development), to produce inventory guidelines giving special attention to village forests.

The guidelines provide the knowledge base for planning and implementation of nationwide village forest inventories, which may be either integrated with or conducted independent of a national inventory of forests. The focus is on village forest conditions, as there is very little organized knowledge existing on these surveys. An immediate question may be asked: is there a need for two national surveys - one on village forests and the other on conventional forests - the concept of forest being defined by crown density. Should not one work out a procedure that gives all the knowledge in one national inventory? The answer very much depends on the political and administrative setting of a country, the need for such information as well as the existing country capacity in forest inventory. Ideal, of course, is one integrated survey. In view of this, the guidelines describe techniques, which may be used in case of an integrated inventory or to an inventory of village forests alone.

People familiar with participatory methods geared to assess the specific needs of local population may find the guidelines described here top down or traditional. Dr. Singh takes the perspective that this approach is necessary based on the scope of assessment, which is here national. The guidelines are intended for use by national level forest inventory specialists to orient them to problems in the survey of village forests including size and shape of the sampling unit, stratification, sampling procedures and special studies related to measurement of non-wood products. Village forests can differ significantly from other forests in many respects such as the spatial patterns, density, form and end use of trees. These differences call for an adaptation of the knowledge contained in the classical forest inventory books and guidelines. The guidelines contain topics and examples chosen with a view to facilitating the process of adaptation and of making the task of designing and analyzing village forest inventories by forest inventory specialists more efficient. 
It is hoped that these guidelines will help stimulate debate about these and alternative systems for national assessment of village forests and stimulate the interest of a wide range of government, NGO and university groups for further work in this important field where the current knowledge base is presently very limited.

The Editors

CIFOR 


\title{
Guidelines on \\ National Inventory of Village Forests
}

\author{
K.D. Singh ${ }^{\star}$
}

\section{Abstract}

This report presents guidelines which provide a basis for planning and implementation of nationwide village forest inventories integrated with or independent of a national forest inventory. It provides coverage of survey problems arising from the variety of spatial distribution conditions of forests and trees under village management landscapes. The guidelines cover survey planning, survey design, survey implementation and survey analysis /evaluation. The main issues in the planning phase such as specification of expected results, statistical outputs and precision of results are discussed. The emphasis in survey design is on definition of survey area, construction of a sampling framework and use of remote sensing data to supplement the field observations. In survey implementation, data must be collected in a consistent manner and with a minimum of bias or non-sampling errors. The importance of good management of the field survey team(s) is stressed. The data processing phase of an inventory includes establishment of an error-free database, analysis and reporting. For the purposes of a national inventory, it is essential that the database and results are well-documented and archived so that the planning at the next cycle of inventory can profit from the past experience and the survey conducted in a consistent manner to estimate changes. Survey evaluation, a retrospective phase not included in most inventories, is considered important in village forest inventories for which the knowledge base to guide inventory planning is very limited.

\footnotetext{
"Center for International Development, Harvard University, Cambridge, USA
} 


\section{Introduction}

This paper presents guidelines on national inventory of trees and forests occurring in rural landscapes, called hereafter 'village forests'. In spite of the great importance to the local community, these resources have often been overlooked by land management agencies. Reliable information on their contributions to the rural economy will help in raising awareness of policy-makers and mobilise support for their management and development.

The guidelines provide a basis for planning and implementation of nationwide village forest inventories, which may be either integrated with, or conducted independently of, a national inventory of forests. The focus is on village forest conditions, as there is very little organised knowledge existing on these surveys. Is there a need for two national surveys, one for village forests and the other for conventional forests? Should there not be a procedure that provides all the information in one national inventory? The answers very much depend on the political and administrative setting of a country, the need for such information and the level of existing forest inventory expertise. An integrated survey is highly desirable and so these guidelines describe techniques which may be used for an integrated inventory or for an inventory of village forests alone. The only difference from the existing literature on forest inventories is that this document provides more detailed coverage of survey problems arising from the variety of spatial distribution conditions of forests and trees in village management landscapes.

The guidelines are organised under four main themes: survey planning, survey design, survey implementation and survey analysis /evaluation. The main elements by theme are listed in Table 1 .

Section 2 begins with the forest inventory problem formulation, answering the question: 'Why is an inventory needed?' It provides a broad classification of forest inventories and objectives of a national inventory. These could include: (1) to arrive at national/provincial wood/non-wood products balance and changes over time; (2) to develop policy or plans for increasing production from village forests to meet growing needs of the community and (3) to evolve a strategy for the effective management of village forests. Section 3 outlines the main issues in the planning phase including detailed specification of expected results, statistical outputs, graphs, equations, precision of results and allowable cost of inventory. 
Table 1. Main elements of the guidelines

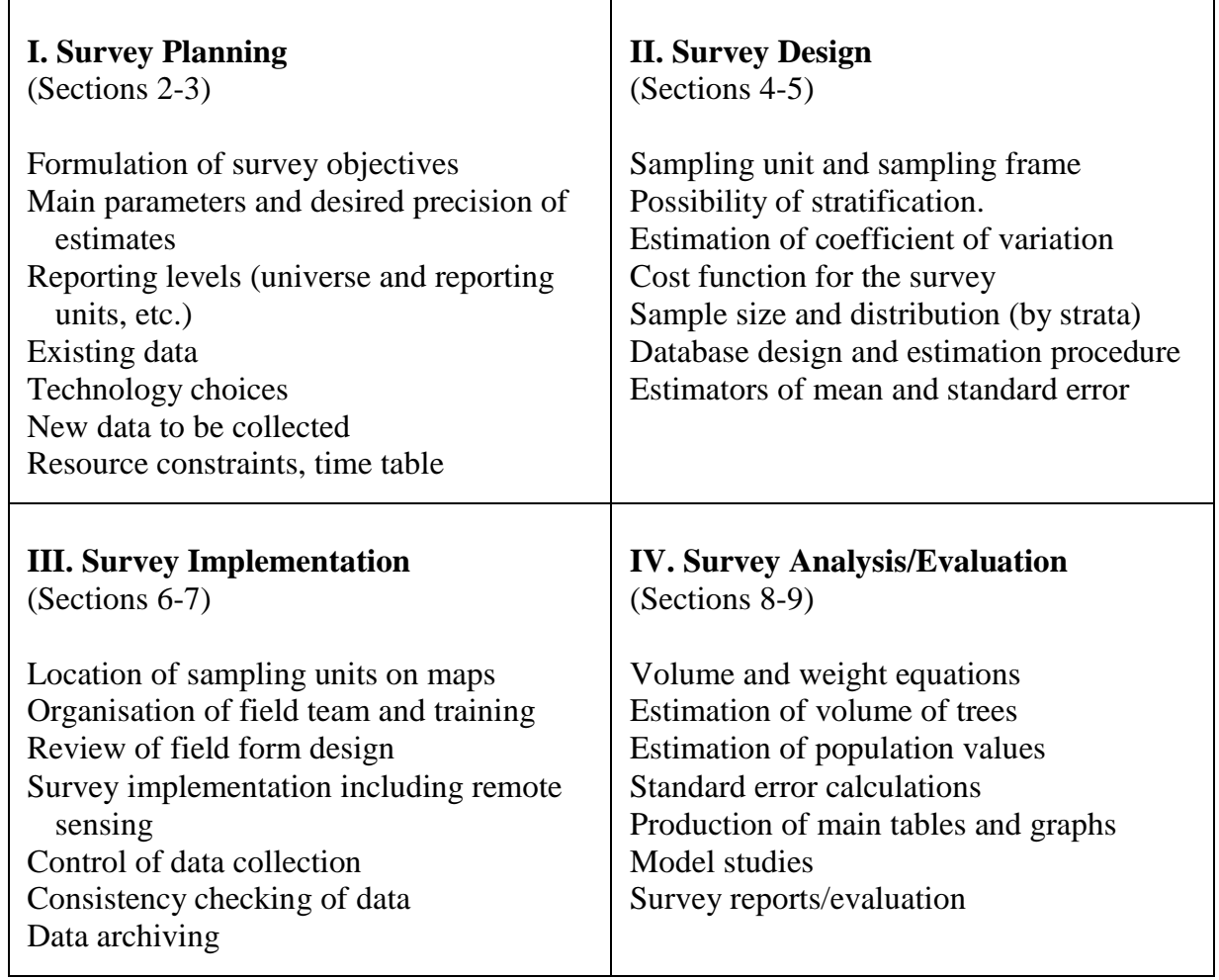

Section 4 discusses matters related to the survey design. The emphasis is on definition of survey area and construction of a sampling frame which involves decisions on size and shape of plots, the possibility of stratification to reduce the standard error, distribution and size of sample, formulas for calculation of means and standard error, etc. Section 5 describes the use of remote sensing data to supplement the field observations.

Section 6 describes survey implementation and Section 7 special studies. It is emphasised that good data is critical to any inventory, in or outside forests. No amount of subsequent analysis can improve the limitations imposed by the data. Data must be collected in a consistent manner and with a minimum of bias or nonsampling errors. The importance of good management of the field survey team(s) is stressed.

Section 8 elaborates the data processing phase of an inventory including establishment of an error-free database, analysis and reporting. This phase is relatively straight forward if survey planning and design have been well done. 
A data processing specialist can help achieve a maximum return from inventory investments. For the purposes of a national inventory, it is essential that the database and results are well documented and archived so that the planning at the next cycle of inventory can profit from the past experience and, more importantly, conduct the survey in a consistent manner to estimate changes. Section 9 is concerned with survey evaluation, a retrospective phase not included in most inventories. This is worthwhile, especially in the case of village forest inventories for which the knowledge base to guide inventory planning is very limited.

Annex 1 presents a brief overview of technologies such as geo-positioning and, geographic information systems and modeling to develop scenarios based on inventory data. These developments have the potential to reduce the cost of inventories, to enhance the depth of inventory data analysis and to influence the quality of final report. They in no way reduce the importance of good data collection. Finally, Annex 2 discusses forest inventory institutions and human resource development, which are very important in the context of continuous forest inventory.

Those familiar with participatory methods geared to assess the specific needs of local population may find the guidelines described here as having a 'top down' approach. This is necessary due to the nationwide scope of the assessment. The guidelines are for forest inventory specialists to alert them to problems in a national-level survey of village forests. Village forests can differ significantly from other forests in many respects including spatial patterns, density, form and end use of trees. These differences call for an adaptation of the classical approach to forest inventory. The guidelines contain topics and examples that will facilitate the process of adaptation and make the design and analysis of village forest inventories more efficient. It is intended that they will stimulate interest and debate about alternative systems for national assessment of village forests and encourage government agencies, non-government organisations and universities to support more work in this important field. 


\section{Problem formulation}

\subsection{Introduction}

The problem formulation provides a detailed specification of forest inventory objectives, in particular, why an inventory is needed. This is the foremost task in any forest inventory. Then one can proceed through stages of data definition, statistical design, data collection and data processing. An inadequacy at the problem formulation stage is most difficult to offset subsequently. Even the best statistical design or use of the most sophisticated remote sensing technology cannot make up for failures at the conceptual stage.

It is emphasised that an inventory is not an end in itself but only a component of a larger decision-making process. Often, decision makers have only a vague idea of the problem and may not be in a position to state precisely their information requirements. Inventory experts usually limit their role to technical issues and do not make adequate efforts to fully understand the problem. This creates a communication gap, which may adversely affect or defeat the very purpose for which the survey was commissioned. Ideas often become clearer as inventory proceeds and more information is available. The inventory designer has to make a special effort to master the planning problem in as much detail as possible and make provisions for new information likely to be requested. This is especially true of the planning process in developing countries where a tradition of national inventories is generally lacking.

\subsection{National forest inventory objectives}

Nilsson (1974) groups forest inventories into two broad categories: strategic and tactical. Strategic inventories address the information needs of policy makers and long-term planners. The lowest unit for reporting is a district and the time horizon five to ten years. Tactical inventories assist forest managers in management planning. The lowest unit for reporting is a forest stand (or community forest or a farm) and the time horizon for recommendations is one year or less.

A national forest inventory is strategic. According to Nilsson, it aims to meet the information needs of planners developing a strategy for satisfying the present and future needs of the society. These needs include forest products and the protective and recreational functions of forests (and trees). They take into account the competing claims from other sectors, mainly agriculture, and the urgency for creating employment opportunities, particularly in the rural areas.

National forest inventories also enable forest production and consumption studies at country, state and regional levels. A civil district constitutes a suitable unit for 
policy measures to meet community needs for forest products. The objective is to estimate the balance (or imbalance!) between the current or projected use of tree products by the community and the potential harvest. This information is necessary for planning to meet local needs for small timber, fodder and fuelwood; and for small enterprises based on forest products. The main survey elements include:

- $\quad$ assessment of existing forest and tree resources;

- estimates of availability of wood or non-wood products from the existing resources; and

- $\quad$ study of past trends and future prospects based on assumptions for rehabilitation of waste, degraded or marginal lands, farm forestry and forest management options.

An example of a production-consumption study is presented in Section 9.5.

The foregoing discussion shows that national policy-makers and planners need information on state forest reserves and village forests, as they complement each other in meeting the needs of the society

\subsection{Emerging issues in setting inventory objectives}

Most national forest inventories provide information for planning, especially wood production. Forestry for food and people is of particular importance for villagemanaged forests. On a global level, there is now an increasing awareness of the importance of forests and trees for the human environment. Inventory information to assist policy formulation and management of these matters has been deficient as production of environmental services, and non-wood forest products are rarely included in inventory objectives.

Planning in the forestry sector cannot be independent other sectors, especially agriculture. It is therefore necessary to create a classification system which will make it possible to identify primary area produce (goods and services) and, ultimately, to estimate and compare the value of alternative sets of products (production alternatives). Singh and Nilsson (1974) present a broader concept of forest production to cover all commodities, services and environmental functions. They define 'primary area production' as a process within an area unit that creates services and commodities that may be beneficial for humans and could be utilised by them. The primary area production may be past, actual or potential, natural or influenced by man. It includes both forest and agricultural production. Forest production (the broader concept) includes all processes and activities related to the production of environmental services and all forest produce. In many developing countries non-wood forest products are of great importance. Secondary area production is defined as the harvesting and transport of primary produce to a 
delivery (consumption) point. Tertiary production is defined as conversion processes beyond delivery point in industries or elsewhere.

Using these definitions, objectives of a national forest inventory (including inventory of village forests), can be stated. A national forest inventory should provide information on primary and secondary forest production for the planning and control of the forestry sector. It should contribute to a better knowledge of different land use alternatives. This is especially important for developing countries where land use changes are frequent and village forests are expected to gain importance in terms of area and production.

\subsection{Problem formulation for a national inventory of village forests}

Tropical forests are receding rapidly due to increasing population pressure, the forest area by the end of 1990 was 1750 million ha and deforestation during 198090 was 154 million ha (FAO 1995). The forest area loss ( $0.8 \%$ per year) and increasing population (2.4\% per year) are not only increasing the pressure on forests but also resulting in a very uneven distribution: 15 countries had 1200 million ha of forest whereas 75 countries had 550 million ha. Estimates of the FAO Agriculture Department show that there is still a need for land to be transferred from forests to agriculture to satisfy the subsistence needs of the growing population. The turning point probably will be when the productivity increase within the agriculture sector is big enough to balance the population growth. These statistics highlight the decreasing importance of natural forests and increasing importance of planted forests for meeting the growing needs for timber, fuel and fodder as well as for environmental conservation and aesthetic purposes.

For simplicity, the term 'village forests' will be used to refer to all forms of woody vegetation managed by villagers. Planted trees occur in a variety of forms: scattered; in lines along the edges of roads, canals and railways; in windbreaks or shelterbelts; on borders of farms and ponds; in clusters in homesteads; or in compact blocks on non-agricultural lands. The term also includes natural forests managed by communities, very open forests with a crown cover less than $10 \%$ and shifting cultivation. The trees are used for a variety of products and environmental services. This report focuses on inventories of planted forest resources, since this is where alternative methods are expected to be most needed.

Village forests are a major land use in many parts of the tropics. In Java (Indonesia), homestead gardens and tree crops alone cover 46\% (6.1 million ha) of the geographic area, whereas state forests account for only $23 \%$ (3 million ha). Bangladesh and the state of Kerala (India), have similar landscapes to Java. Even in dry regions e.g. Haryana (India), northwest Pakistan and northern China, the local people have planted trees for multiple uses in the limited space available. 
Information is needed on current production and consumption from village forests, analysis of existing resources and past trends. There is evidence showing that the contribution of village forests to wood production is very significant and in some countries exceeds that from forests. The farm forestry sector in India by end of 1990 produced 135 million tons of wood and satisfied nearly $50 \%$ of the total country needs. In Bangladesh, homestead gardens accounted for 50\% of timber and $70 \%$ of fuelwood production.

The contribution of village forests are of global significance when the standing biomass and annual wood production in the tropics are aggregated. Opportunities for afforestation and rehabilitation are high due to the availability of significant areas of deforested and degraded lands. The forests raised could have significant environmental benefits and positive social and economic impacts. There is no doubt that the importance of tree planting in village forests will grow in future throughout the tropics.

\subsection{Examples of village forest inventories}

These examples of village forest inventory illustrate the formulation of survey objectives and planning.

The Bangladesh Village Forests Inventory (Hammermaster 1981) may have been the first nationwide assessment of trees outside reserved forests. The stated purpose was, 'to undertake a national inventory of both the major and minor forest produce resources of the village (or homestead) areas.' It aimed to achieve a result within an approximate sampling error of $10 \%$ at a $95 \%$ probability level on a national basis. Additional ancillary studies were required on village raw material supplies to selected industries.

Forest Survey of India (1995) stated the following objective in a survey of Haryana State: 'assess the availability of forest resources for the production of timber, fuelwood and raw material for paper pulp, packing cases, essential oils, matchwood, etc. in outside reserve forests areas and those forest areas which could not be covered during the course of the regular inventory work.'

The Forestry Faculty, Bogor Agricultural University (1986) made a more detailed specification of forest inventory for a study of fuelwood in Java (Indonesia). The goal was, 'to collect data on the biomass and fuelwood potential and fuelwood supply in the province of West Java, focussing particularly on fuelwood produced outside forest land. The data will serve for analysis of areas of fuelwood surplus and shortage and for the preparation of biomass production options'. This study included observations on degraded lands and prospects for increasing fuelwood production. The biomass potential included 'the standing stock or growing stock of the existing vegetative cover in the village agricultural land, homestead gardens, 
etc., excluding roots, fruit and leaves'. Fuelwood potential was defined as 'that portion of the biomass potential, which cannot be used as construction wood because of the nature and (small) size of the assortment concerned. The fuelwood potential includes trees that could be used for more valuable purposes but will still be used as fuel. Fuelwood supply is that portion of the fuelwood potential, which can be harvested annually as fuelwood on a sustainable basis. This means, that the allowable supply does not exceed the average (annual) biomass increment'.

Limiting the objective of a national inventory to just what is growing in village forests is very narrow. A wider context, as in the Indonesian study, should include production-consumption studies and expansion of the community resource base to meet future needs and provide income and employment. Data on growth and yield, and cutting calculations are also needed for planning optimal use of resources (see Section 9). 


\section{Survey planning}

\subsection{Introduction}

Knowledge of village forest inventories is limited, whereas the literature on inventories of forest reserves managed by foresters is copious and dates back nearly 150 years. The Bangladesh Village Forest Inventory, conducted by FAO during $1980-82$, is an example of a first systematic effort in the tropics. A survey of hedgerows and trees in the United Kingdom by the Forestry Commission in 198992 is a good example of an inventory in a temperate area (Forestry Commission 1990).

Trees planted by villagers form more scattered units and have more diverse management than large areas of forest or industrial plantations. Figure 1 conveys the variety and complexity of the landscapes under consideration. Individual farmers or communities, growing trees in small areas or in association with their crops, have direct control of species selection and influence tree development by management practices that may be different and more diverse than those used in large plantations.

Figure 1. A landscape in Doon Valley of India showing alternating agriculture and trees (illustration by Indira Singh).

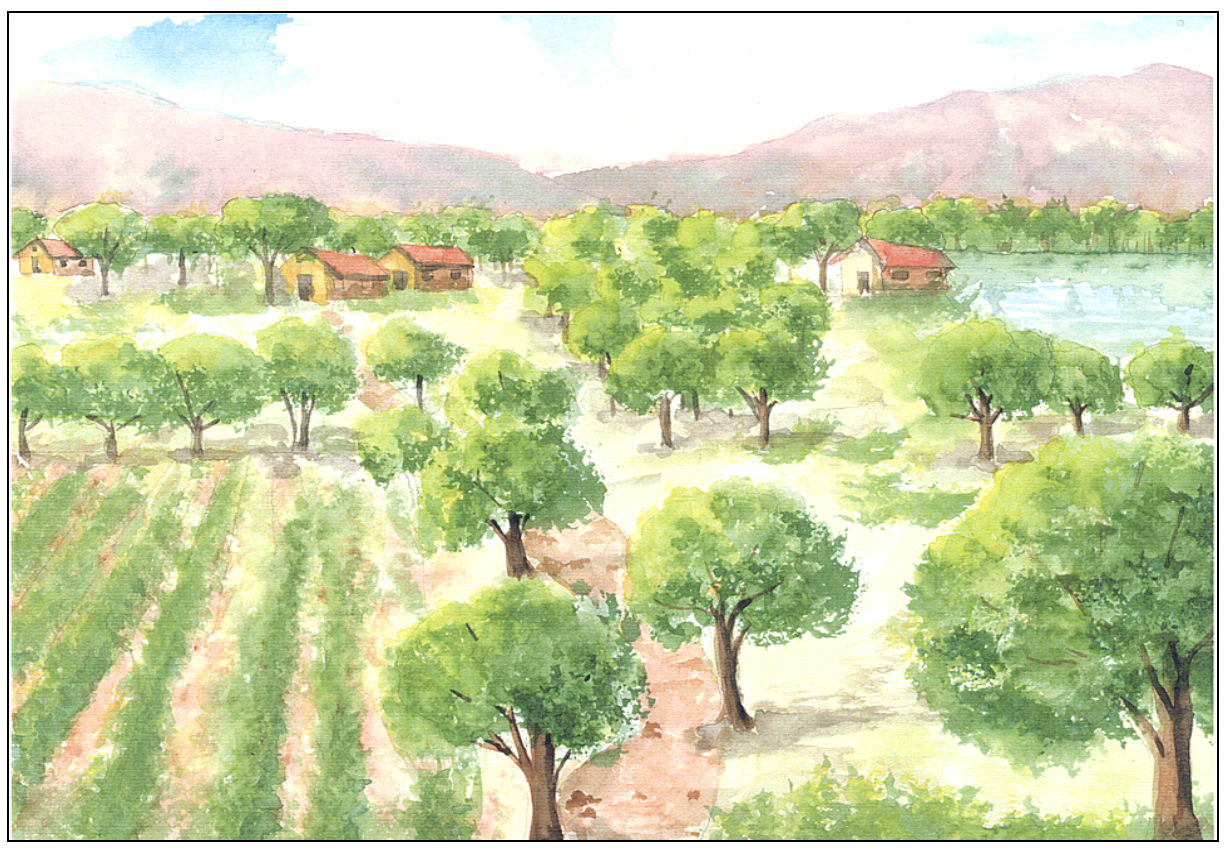


Different inventory situations (Table 2) make it difficult to apply standard forest inventory techniques directly to village forests. Adaptations are required and new procedures developed to match the complexity of site and stand.

Table 2. Differences between inventory of forest reserves and village forests

\begin{tabular}{|l|l|l|}
\hline Inventory elements & Forest reserves & Village forests \\
\hline $\begin{array}{l}\text { Tree spatial } \\
\text { distribution }\end{array}$ & $\begin{array}{l}\text { Regular spatial } \\
\text { distribution in } \\
\text { predominantly closed } \\
\text { stands }\end{array}$ & $\begin{array}{l}\text { May include both } \\
\text { closed and open } \\
\text { stands, varying } \\
\text { patterns }\end{array}$ \\
$\begin{array}{l}\text { Stem form and } \\
\text { volume estimation }\end{array}$ & $\begin{array}{l}\text { Information known } \\
\text { for major commercial } \\
\text { species }\end{array}$ & $\begin{array}{l}\text { Diverse products, } \\
\text { production and } \\
\text { management } \\
\text { information may } \\
\text { not be available }\end{array}$ \\
Growth and yield & $\begin{array}{l}\text { Information known } \\
\text { for major commercial } \\
\text { timber species }\end{array}$ & $\begin{array}{l}\text { Little known, } \\
\text { especially for non- } \\
\text { timber species }\end{array}$ \\
\hline
\end{tabular}

\subsection{Survey planning check list}

National inventories are time consuming and expensive as they require use of many types of expertise and administrative experience. It is, therefore, important to ensure that they help solve the problem. Often, there is little interaction between the user and the designer of survey, resulting in the survey reports not being used.

The following check list gives the steps used for planning traditional forest inventories and is equally applicable to village forests.

1. Identify the problem which inventory is expected to solve.

2. Review possible approaches to solve the problem.

3. Clarify what information is required.

4. Define the area to be inventoried.

5. Collect and systematise existing information and carefully assess its usefulness to solve the problem under consideration.

6. Decide whether or not a new inventory is necessary. Consider costs in view of existing information, financing, recruitment, institutional and administrative difficulties and time aspects.

7. List data to be collected and assessments to be made.

8. Decide if mapping is required.

9. Define required accuracy for main parameters. 
10. Clarify the need for special studies: volume functions, growth and yield studies.

11. Prepare outline of design and estimation models.

12. Outline measurement techniques.

13. Consider recruitment, staff training and field instructions.

14. Anticipate administrative problems in organising field and office routines.

15. Ensure control of fieldwork.

16. Predict expected end use of results in drafting final report and establishing a data bank.

17. Outline the results required to solve the planning problem.

18. Identify data processing including recording, checking, compilation and data storage.

19. Undertake preparatory investigations.

20. Undertake pilot study.

A proper understanding and execution of these steps will clarify the objectives of the proposed inventory and result in correct specification of data and results. Steps 1 to 3 relate to the inventory problem formulation; steps 4 and 6 to the study of existing data and deciding if a new inventory is required. The limitations of existing data have to be weighed against the cost, finances, recruitment of staff, time involved, institutional and administrative problems, etc. of a new inventory. Steps 7 to 17 relate to a proposed inventory and its elaboration. Having identified the elements of the new inventory (steps 18 and 19), a pilot study may be conducted. 


\subsection{Information need analysis: a matrix approach}

A matrix framework to assist survey planning (based on Nilsson 1978) is given in Table 3.

Table 3. Information needs and sources

\begin{tabular}{|c|c|c|}
\hline Questions and problems & $\begin{array}{l}\text { Existing } \\
\text { information by } \\
\text { source }\end{array}$ & $\begin{array}{l}\text { New } \\
\text { information by } \\
\text { source }\end{array}$ \\
\hline $\begin{array}{l}\text { Total land area (per civil district or smaller unit) } \\
\text { and areas of land classified as eroded, skeletal soil, } \\
\text { lateritic soil, sand dunes, 'wasteland' (1) }\end{array}$ & & \\
\hline $\begin{array}{l}\text { Location (longitude, latitude, altitude), climate, } \\
\text { topography and soils. Growth estimates ( } 2 \text { ) }\end{array}$ & & \\
\hline Relevance of present land use (3) & & \\
\hline Implemented and planned projects (4) & & \\
\hline $\begin{array}{l}\text { Areas of special value for landscape, fauna and } \\
\text { flora (biological diversity) (5) }\end{array}$ & & \\
\hline $\begin{array}{l}\text { Climatic abnormalities and apparent changes of } \\
\text { climate or ground water level, flood damage, and } \\
\text { famine years 1940-2000 (6) }\end{array}$ & & \\
\hline $\begin{array}{l}\text { Supply of water for households and potential } \\
\text { irrigation (7) }\end{array}$ & & \\
\hline $\begin{array}{l}\text { Oil and mineral resources influencing on the land } \\
\text { use pattern (8) }\end{array}$ & & \\
\hline $\begin{array}{l}\text { Non timber products ( non-marketed and rural } \\
\text { market): list of products ranked according to } \\
\text { importance, availability, trends, saturation level. } \\
\text { Volume and value estimates (9) }\end{array}$ & & \\
\hline $\begin{array}{l}\text { Non-timber urban and industrial market: List of } \\
\text { products ranked according to importance. Volume } \\
\text { and value estimates (10) }\end{array}$ & & \\
\hline $\begin{array}{l}\text { Wood including non-wood pulping material: } \\
\text { Actual production and consumption of fuelwood } \\
\text { and other wood for auto-consumption. (11) }\end{array}$ & & \\
\hline
\end{tabular}


Table 3. Continued

\begin{tabular}{|c|c|c|}
\hline Questions and problems & $\begin{array}{c}\text { Existing } \\
\text { information by } \\
\text { source }\end{array}$ & $\begin{array}{c}\text { New } \\
\text { information by } \\
\text { source }\end{array}$ \\
\hline $\begin{array}{l}\text { Same: saturation level, change of consumption } \\
\text { habits. Possible substitutes. Production- } \\
\text { consumption balances 1980, 1990, } 2000 \text { (12) } \\
\text { Same: industrial wood or other forest product } \\
\text { production and consumption studies 1980, 1990, } \\
2000 \text { (per region or state) (13) } \\
\text { Same: consumption trends 1960-2000 (14) } \\
\text { Forest balance: comparison between removal and } \\
\text { growth. Changes of area availability and volume. } \\
\text { Changes in area production 1980, 1990, 2000. } \\
\text { Production scenarios (15) } \\
\text { Actual wood and product balances (including } \\
\text { export, import, recycling, change of stock, } \\
\text { substitutes) for 1980, 1990, 2000, } 2020 \text {. } \\
\text { Development scenarios (16) } \\
\text { Comparison between forest balances and wood and } \\
\text { product balances, past trends, present state and } \\
\text { future scenarios (17) }\end{array}$ & & \\
\hline
\end{tabular}

The sources of information are:

\section{Existing information}

- Survey maps

- Forest Department files

- Cadastre registers

- Existing forest inventories

- Literature search (specify report)

- Central bureau of statistics and other sources

New information to be collected

- New mapping, remote sensing, GIS

- Field inventories

- Consumption studies and inquiries

- Special studies 


\subsection{Consistency between national inventories of village forests and forest reserves}

When national inventories in and outside forests are conducted separately, they should use a consistent definition, approach and a common land use classification (Figure 2) to obtain a national total in terms of area, growing stock, increment and removals.

\subsection{Delineation of survey universe}

The two inventories should also delineate their respective survey universe using an identical reference map, e.g. national survey, land use or forest cover map, to prevent discrepancies between them. In Asia and the Pacific Region, most of tropical countries have forest cover maps at 1:1 million or larger scale made during 1980-90; and have established institutions for forest cover mapping and for producing and updating forest resources statistics. These maps, statistics and associated documents are valuable for survey planning and ensuring consistency between national inventories in and outside forests. A comprehensive inventory design treating village and other forest areas as two strata is the ideal solution. 
Figure 2. An example of a common land use and forest classification

OVERALL LAND CLASSIFICATION

Total Area (1.1)

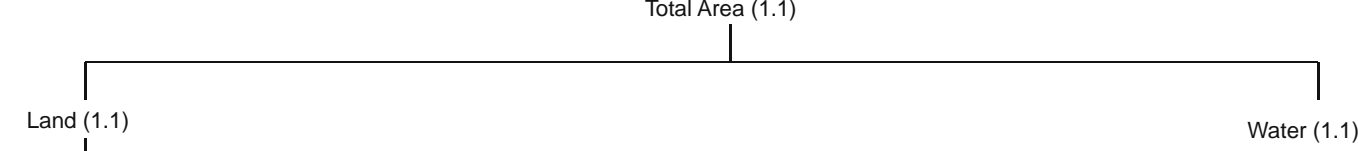

Forest and other wooded land (1.1.1.2)

Non-forest land (1.1)

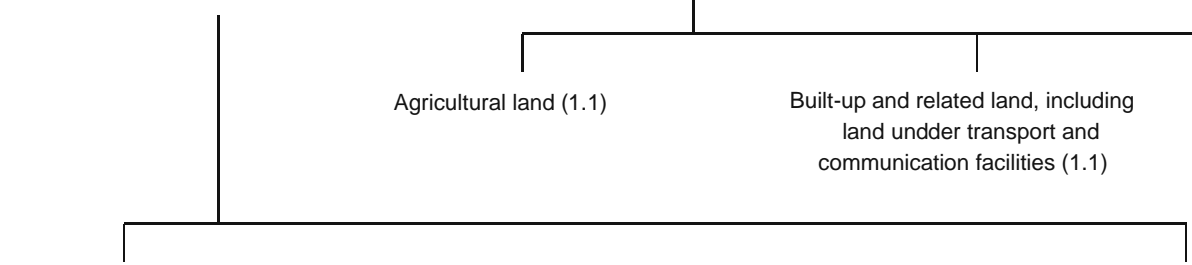

Closed forest (1.1 1.21 .3$)$

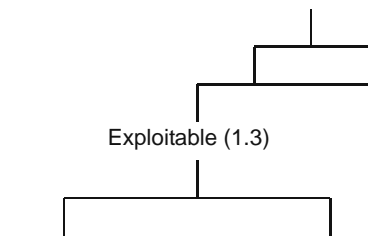

Unstocked (1.3) Unstocked (1.3) reserves $(1.3)$

Other (1.3)

Unexploitable (1.3)
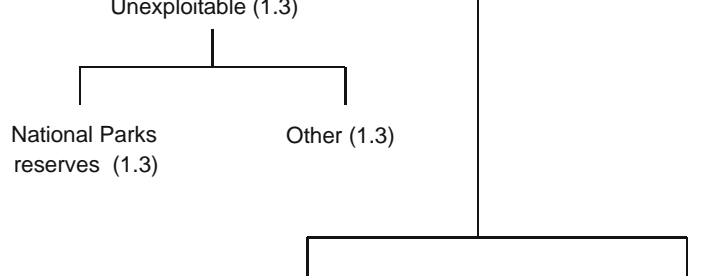

High forest (1.2)

Numbers in brackets refer to the tables in which the information is shown

Source: FAO (1995)
Coppica and coppica with

standards (1.2)
Other wooded land (1.| 1.2)
Areas occupied by windbreaks, shelter-belts, isolated groups of trees, etc. (1.2)
Other (1.1) 


\section{Survey design}

\subsection{Introduction}

The reasons for using a sampling technique other than a census are to obtain estimates with specified precision at the least cost; and provide an objective basis for collecting data and making inferences about the parent population. Sample survey estimates are always subject to a variety of errors arising from field sampling, measurement and judgement. The errors follow the law of propagation of errors. It is important that the user of the survey specify at the very outset, the desired standard error and level of confidence. For example, surveys in Bangladesh and Haryana (India), both set the standard error goal at $10 \%$ and confidence level at 95\% (Hammermaster 1981, Forest Survey of India 1995). These are only approximations as the final error would rarely be the same.

The cost and variance (square of the standard error) together, define the efficiency of a sample survey design expressed as follows:

$$
\mathrm{E}_{(1,2)}=\mathrm{C}_{(2)} \cdot \mathrm{V}_{(2)} / \mathrm{C}_{(1)} \cdot \mathrm{V}_{(1)} \cdot
$$

where $\mathrm{E}$ is efficiency, $\mathrm{C}$ is cost and $\mathrm{V}$ is variance of a survey. The subscripts 1 and 2 denote the two survey options under comparison.

\subsection{Sampling frame, size and shape of sampling units}

The survey area needs to be subdivided theoretically into sampling units. The sampling units remain 'theoretical' until it is confirmed that it is possible to locate them on the ground. There are no hard and fast rules to define the size and shape of a sampling unit. It could be a strip, rectangle or square with an area of 0.1 ha, 0.5 ha, etc. Most inventories in Asia have taken an administrative village as the sampling unit.

The size and shape of a sampling unit have important implications for the cost of measurement and the standard error of the survey. Generally, the coefficient of variation (standard error expressed as \% of the mean) decreases exponentially as the sampling unit size increases. However, the cost also rises with the increase of area and there may be associated non-sampling errors, e.g. the tendency to miss some trees in large sampling units. The sampling unit's shape may also influence on the error. In units of the same area there are more border trees in a strip than in a square and this increases the probability of making an error in including or excluding trees. A circle has the least perimeter for a given area and thus has less border trees. 
The choice of a village as a sampling unit is good if the purpose is to make a production and consumption balance or to integrate inventory with socioeconomic data for forestry development planning. An examination in the field must be made to determine if the administrative village corresponds with the land use of actual settlements.

\subsection{Sampling plan}

Only a brief account of sampling theory is provided with some remarks relevant to inventory of trees outside forests. Standard textbooks, e.g. Cochran (1965) give detailed description of designs.

For the purposes of these guidelines, survey designs have been categorised as follows:

- $\quad$ Single date assessment no secondary information used, or values of an auxiliary variable developed from secondary sources known for all sampling units during survey planning, or values of auxiliary variable from secondary sources become available after completion of field inventory

- Multi-date assessment (also called continuous forest inventory)

The choice of multi-date over single date survey is guided by the need to assess changes. National forest inventories are in the multi-date assessment second category. Multi-date satellite data or aerial photographs provide a consistent way to estimate changes in land use. Geo-positioning systems can assist in accurate location of plot sites and changes in growing stock can be examined through use of permanent (hidden) sampling units.

'Auxiliary variable' refers to data collected from sources other than the field inventory, e.g. aerial photo-interpretation, past census, socioeconomic or ecological surveys. In the surveys in India and Bangladesh (Hammermaster 1981, Forest Survey of India 1995) census records for the villages were used. Auxiliary data may be available at the time of survey planning or when the field inventory has been completed. Based on availability of secondary information, the standard sampling options may be: 
No auxiliary variable used in inventory

Simple random sampling

Systematic sampling

Cluster sampling

Block surveys (by topographic or geographic units)

Distance and line intercept methods

Values of an auxiliary variable known used in survey planning

Stratified sampling

Multiphase sampling with:

ratio estimates

regression estimates

Probability proportion to size

Values of auxiliary variable available only later after field survey

Post-stratification of sampling units

\subsection{Non-standard sampling procedures for village forest inventories}

Thompson (1992) and Matérn (1984) describe procedures for village forest surveys. Trees outside forests are often elusive and then the procedure may use 'distance methods', in which the nearest tree or trees from a randomly located point are located and distance measured. Line intercept sampling, in which the distance of trees from a randomly laid out line is recorded, is also used. A distribution pattern of trees is generated from the measured distances. The 'four-sides inventory' in China uses a strip $10 \mathrm{~m}$ wide and $1000 \mathrm{~m}$ long to record trees and forest in villages, around houses, and along rivers and roads (Ranneby 1985). Smith and Phillips (1992) used 'line intersect sampling' to assess biomass by block (a subdistrict unit) in Andhra Pradesh State (India) characterised by discontinuous nature of vegetation. In each administrative block six transects, $100 \mathrm{~m}$ x $200 \mathrm{~m}$, were measured. The values of total biomass and associated standard deviation by block showed wide variation which suggests that stratification of blocks or use of probability proportional to estimated size could have reduced the sampling error.

\subsection{Sample size}

The sample size, i.e. the number of sampling units, is a function of the sampling plan and inherent variability of the population to be surveyed. The sampling units may be selected using any of the procedures described in the earlier section depending on the availability of auxiliary information and cost of survey associated with alternative schemes. For each procedure, there is an appropriate formula for 
estimating the mean and variance (square of standard error) as a function of the number of sampling units. To compute the required number of sampling units for a given level of standard error, the statistician must be able to approximate the variance and cost associated per sampling unit for the population under consideration. In most situations it may be enough to use past experience but pilot studies, using a small sample of units, should be made in more complex situations.

When the population is subdivided into subpopulations, as in stratified sampling, allocation of sampling units to strata requires further consideration. One of two standard approaches is used: sampling units are distributed to strata proportional to their area; or sampling units are allocated proportional to variance of strata. The latter is also known as 'optimal allocation' or 'Neyman allocation'. Proportional allocation is useful when stratum means vary significantly whereas optimal allocation is used when means and variances vary significantly among strata.

\subsection{Subsampling and recording units}

Sampling is designed to achieve the precision goal for main variables such as species and diameter of trees. Subsampling may be used for measuring variables e.g. tree height, regeneration, crown size, etc., which are time consuming and expensive to measure and of less importance than the main variables. For this purpose, sampling units are divided into smaller recording units e.g. $25 \%$ or less. Measurement of secondary parameters is confined to subunits only.

\subsection{Special studies}

Special studies are usually conducted independently but may be conducted using a part of subsampled trees. The same is true for non-wood products, such as bark or fruit yield associated with sampled trees. Special studies contribute to the survey by providing the coefficient of functions to make derived estimates with the help of sample survey data. Estimation of tree volume and biomass measured in the main inventory is an example. This topic is discussed further in Section 7.

\subsection{Examples of survey procedures}

The use of remote sensing information as an auxiliary variable is very relevant for village inventories (Singh 1986).

Double sampling: In this approach, a survey is organised in two phases. In the first (less expensive) phase measurements are made of selected attributes on a very large number of photographs. Then a small subset of these photographs is selected for the more expensive second phase where measurements are made in the field. The 
sampling units measured in both phases are used as the 'bridge' to estimate or predict the values of all first phase sampling units.

The auxiliary information may or may not contribute to survey efficiency. The critical factor is the cost ratio $(\mathrm{Cg} / \mathrm{Cp})$ and value of correlation coefficient $\left(\mathrm{R}^{2}\right)$ between the primary and auxiliary variable. $\mathrm{Cg}$ stands for the cost per unit of ground information and $\mathrm{Cp}$ that for remote sensing based survey; $\mathrm{R}^{2}$ is the coefficient of correlation between the two sets of parameters. The limiting values are:

$$
\begin{array}{llllllll}
\mathrm{R}^{2} & =0.2 & 0.3 & 0.4 & 0.5 & 0.6 & 0.7 & 0.8 \\
\mathrm{Cg} / \mathrm{Cp} & >18 & 11 & 8 & 6.5 & 4.5 & 3.5 & 2.5
\end{array}
$$

Nichols et al. (1975) investigated the use of remote sensing in combination with field survey (double sampling) for volume prediction in Plumas National Forest, California. The observed value of $\mathrm{R}^{2}$ was 0.6 and $\mathrm{Cg} / \mathrm{Cp}$ was $18 / 1$. In this case the use of double sampling was appropriate. For forests of Bastar, India, $\mathrm{R}^{2}$ was 0.25 and $\mathrm{Cg} / \mathrm{Cp} 12 / 1$ (Singh 1982), so the double sampling technique was not costeffective.

Stratified surveys: The role of aerial photographs for stratification is well established. Their main contributions are elimination of field visits to certain areas and gain of variance by grouping areas into more homogeneous subpopulations than would otherwise have been possible. Gain of variance by stratification depends on correlation between the photo and ground variables (Cochran 1965):

$$
\mathrm{V}(\mathrm{ST}) / \mathrm{V}(\mathrm{SR})=\mathrm{R}^{2} / \mathrm{L}^{2}+\left(\mathrm{I}-\mathrm{R}^{2}\right),
$$

where $\mathrm{V}(\mathrm{ST})$ and $\mathrm{V}(\mathrm{SR})$ are variances of stratified and simple random sampling respectively for the same number of sampling units; $\mathrm{R}^{2}$ is the square of correlation coefficient between the field and photo-characteristics, and $\mathrm{L}$ the number of strata. A limit is set by the term: $\left(I-R^{2}\right)$.

The higher the number of strata, the more types have to be delineated and, therefore, the cost is higher. We can use a cost function of type:

$$
\mathrm{C}=\mathrm{LC}(\mathrm{ST})+\mathrm{n}^{*} \mathrm{C}(\mathrm{SR})
$$

where $\mathrm{C}(\mathrm{ST})$ is cost per unit of stratification, $\mathrm{C}(\mathrm{SR})$ the cost of field work per sampling unit, $\mathrm{C}$ the total cost and $\mathrm{n}$ the number of sampling units. The same formula can also be used to compare two remote sensing techniques, e.g., LANDSAT and orthophoto maps. 


\subsection{A complete case study: survey of trees and hedgerows in the United Kingdom}

The main steps of this survey in the United Kingdom are outlined to convey a complete sequence of survey steps (Forestry Commission 1990, pages 1-10).

\section{Statistical planning}

A sample scheme was chosen to give $10 \%$ standard error on the total number of isolated tress in a county/administrative district group, underpinned by $20 \%$ precision on major species.

Data was collected using a two-phase sample survey design including an aerial photograph survey; and ground visits. The first estimate of the isolated tree population was found from a pilot survey.

The following studies were implemented as a part of statistical planning:

- The 71 soil strata from the Soil Survey of England and Wales were combined into 16 strata.

- The boundaries of all counties and soil strata were regularised to the nearest $1 \mathrm{~km}$, the counties by hand and the soil strata by laser scan.

- The pilot survey revealed, within each county stratum, the performance of each soil stratum in terms of numbers of isolated trees and variance. Soil strata with similar population and variance were combined with sampling strata.

- The computer was programmed to produce a map showing regularised county and soil strata boundaries, overlaid with a grid of $0.25 \mathrm{~km}$ squares. The squares were combined into clusters of six squares by hand, and the clusters numbered within each soil stratum within each county.

- Using the results of the pilot survey, the Statistics Section decided the number of sample units required to achieve the desired precision.

- Maps at scales of 1:50 000 and 1:10 000 were marked up with both the woodland and hedgerow samples. Ground visit samples were differentiated from aerial photograph samples. A check was made if the aerial photograph cover was available and photographs ordered at 1:10 000 scale from Ordinance Survey and commercial photography from the Forestry Commission on 1:50 000 maps where no other cover was available. 
Field survey, remote sensing and data processing

Remote sensing and field surveys included:

- Assessment from photographs of all the clusters in the sample to give data on the numbers of isolated trees, crown diameters, areas of clumps, lengths of lineal features and the location of the various tree features, i.e. open grown or on a boundary, roadside, railside, parkland etc., and

- Assessment on the ground of a subsample of the interpreted photos to gather information on species, diameter, total height, timber height, health and type of boundary.

Any woodland not shown on the 1: 50000 map was noted during hedgerow ground survey.

The main data processing steps were:

- All data was recorded on an electronic data capture machine, either in the field or in the office.

- Data was transmitted to a central location for validation. The surveyors again checked print outs before the final version of the data was stored permanently. and

- The field data was analysed to give mean values per square and used to 'correct' the photo-interpretation results. The data from the ground visit was analysed to give species, diameters, volume and site distributions.

\subsection{Sample survey check-list}

The main sampling options in a national forest inventory are:

Nature of sampling unit

- Mono-areal plots

- Poly-areal plots

- Mixed system

- Non-area sampling

Type of sampling unit

- Line

- Cluster (plot)

- Unit

- Tree 
Number of recording units per sampling unit

- One recording unit per sampling unit

- More than one recording unit per sampling unit

Division of recording unit

- No

- Yes

Phases of sampling

- One-phase

- Two-phase (double sampling)

Stratification

- No stratification

- Stratification a priori

- Stratification a posteriori

Stages of sampling

- One-stage

- Two-stage

Size of primary sampling unit

- Equal size

- Unequal size

Selection of secondary sampling unit (in 2-stage)

- Random

- Systematic

Size of secondary sampling unit (in 2-stage )

- Equal size

- Unequal size

Stratification in first stage of second stage sampling

- No stratification

- Stratification

Selection of secondary units in second stage sampling

- Random

- Systematic 


\section{Role of remote sensing}

\subsection{Introduction}

The term 'remote sensing' is used here to include aerial photographs and satellite images for obtaining auxiliary information as a part of the field survey (see Section 6). Aerial photographs at larger scales e.g. 1: 5000-10 000, can provide a good synoptic view of trees in a village and its surrounds, location of each individual tree and pattern of tree distribution. Adjacent pairs of photographs enable a stereoscopic (3-dimensional) view and tree or stand measurements which can be combined with field inventory data. This permits a major part of the survey work is done on photographs with only a minor part in the field using a double sampling approach.

Tree and stand level measurements are not feasible with smaller scale images (aerial photographs at 1:50 000 or smaller scale, SPOT/Thematic Mapper and LANDSAT Multispectral Scanner, Indian Remote Sensing Satellite). However, it is possible to use them for, classification and mapping areas by density and broad vegetation types. This is useful for division of the survey universe into more homogeneous subpopulations or strata. Sampling error and mean are estimated within each stratum, and then combined to obtain population estimates using statistical formulas.

\subsection{Application of remote sensing}

Remote sensing can support inventory of trees outside forests in many ways (Singh 1982, 1986):

\section{Classification and mapping}

Mapping (or geo-referencing) is one of the most important and cost-effective use of imagery, which can be very expensive if based on ground surveys alone. The mapping can be at the level of individual objects or at the level of the landscape. Depending on the resolution, single trees, trees in line or tree clumps could be interpreted and mapped. At the landscape level, density or broad types of landscape features can be interpreted and mapped. 


\section{Provision of auxiliary data (by interpreting attributes of objects).}

This may take many forms:

- Count of trees;

- Length or area associated with trees in line or strips;

- Species;

- Crown density of trees in a plots or density of trees in a strata;

- Crown diameter of single trees or average crown diameter of trees in a plot; and

- Tree or plot volume estimation using single tree or aerial stand tables.

If maps are not required, objects or landscape features can be interpreted directly on imagery on a complete interpretation or sampling basis. For the latter, there are many options, e.g. point, line (or transect) or plot sampling.

The availability of multi-date images with their increasing resolution and spectral coverage, has opened up new possibilities for the monitoring of changes in area, volume and forest condition. Historical change assessments have become possible by comparing existing records with the present situation.

\subsection{Integrating remote sensing and field surveys}

Information generated by remote sensing images and field data can be combined in many ways, e.g. stratification, probability proportion to size or double sampling. As remote sensing generally provides only part of the whole database, it is very important to consider possible problems when combining remote sensing and field survey data. It may appear simple, but in practice, any synthesis of data originating from different sources presents difficulties at the time of compiling the information due to the incompatibility of concepts, and sampling and non-sampling errors. This should be given adequate attention in the design phase of an inventory.

Generally, the error is very high at species level classification with LANDSAT. Only broad types of classification such as forest and non-forest or broad density classes, low, medium and high stocking or density are useful. 


\subsection{Using satellite remote sensing to detect changes}

Area changes can be monitored by map to map comparisons or image to image change assessment. The crucial factors affecting the accuracy of the multi-date LANDSAT studies are the accuracy of registration of data and size of the block in relation to the resolution of the sensor.

FAO's 1990 forest resources assessment developed a new approach to change assessment which has been termed 'interdependent interpretation procedure' (FAO 1996). In this procedure, two images, acquired about ten years apart, are interpreted in a single interpretation process. Each class boundary is based on both images, thus eliminating the error arising from registration of two data images. Consequently, the changes are directly observed and not derived from the difference between two independent interpretations.

In principle, this analysis can be carried out digitally as well as visually but in practice the digital approach is not yet able to cope with subtle external variations (noise) in each image due, for example, to haze and shadows or seasonal variations in vegetation appearance. The advantages of being able to compare the two data sources and effect continuous relative adjustments make the visual approach the most suitable.

The classification scheme is hierarchic (Table 4). Forest and non-forest are the two main classes, which should meet the needs of both national forest and national agriculture inventories. Within each major class, subclasses may be distinguished depending on the resolution of the sensor. The interdependent procedure gives not only an estimate of change, but also reveals where the deforestation is occurring and what is happening to the deforested land (Table 5).

The entire area of change detection, including visual and computer-assisted interpretation, has developed very fast during the recent years, especially with the availability of images from second and now third generation satellites. 
Table 4. A hierarchic classification of land use and forest cover classes

\begin{tabular}{lll}
\hline $\begin{array}{l}\text { Land use } \\
\text { categories }\end{array}$ & Land cover groups & \multicolumn{1}{c}{ Land cover classes } \\
\hline Forests & $\begin{array}{l}\text { Natural forests: } \\
\text { Continuous forest }\end{array}$ & $\begin{array}{l}\text { Closed forest } \\
\text { Open forest } \\
\text { Long fallow } \\
\text { Fragmented forest }\end{array}$ \\
& Fragmented forest & Forest plantations \\
& Plantations & $\begin{array}{l}\text { Agricultural plantations } \\
\text { Shrubs }\end{array}$ \\
& Plantations & Short fallow \\
Other woody vegetation & Water land cover
\end{tabular}

Table 5. Change matrix at the Sampling Unit 4409 in Northeast India - Period covered: December 1981 - February 1988

\begin{tabular}{|c|c|c|c|c|c|c|c|c|c|c|c|}
\hline \multirow{3}{*}{$\begin{array}{l}\text { Interpretation } \\
\text { classes of } \\
\text { historical } \\
\text { image }\end{array}$} & \multicolumn{9}{|c|}{ Interpretation classes of recent image (thousand hectares) } & \multirow{2}{*}{\multicolumn{2}{|c|}{$\begin{array}{c}\text { TOTAL } \\
\text { Historical } \\
\text { image }\end{array}$}} \\
\hline & \multirow[t]{2}{*}{$\begin{array}{l}\text { Closed } \\
\text { Forest }\end{array}$} & \multirow[t]{2}{*}{$\begin{array}{l}\text { Open } \\
\text { Forest }\end{array}$} & \multirow[t]{2}{*}{$\begin{array}{c}\text { Long } \\
\text { Fallow }\end{array}$} & \multirow{2}{*}{$\begin{array}{l}\text { Frag- } \\
\text { mented } \\
\text { Forest }\end{array}$} & \multirow[t]{2}{*}{ Shrubs } & \multirow[t]{2}{*}{$\begin{array}{l}\text { Short } \\
\text { Fallow }\end{array}$} & \multirow{2}{*}{$\begin{array}{l}\text { Other } \\
\text { Land } \\
\text { Cover }\end{array}$} & \multirow[t]{2}{*}{ Water } & \multirow[t]{2}{*}{$\begin{array}{c}\text { Planta- } \\
\text { tion }\end{array}$} & & \\
\hline & & & & & & & & & & ‘000 ha & $\%$ \\
\hline Closed forest & 1078.0 & 0.8 & 46.0 & 21.6 & 1.2 & & 25.2 & & 2.4 & 1175.2 & 42.0 \\
\hline Open forest & 0.8 & 40.8 & & 0.4 & 1.6 & & 1.6 & & & 45.2 & 1.6 \\
\hline Long fallow & 6.0 & & 683.6 & 80.8 & 12.0 & & 47.2 & & 0.4 & 830.0 & 29.7 \\
\hline Fragmented Forest & 6.8 & & 18.4 & 80.8 & 0.4 & & 7.6 & & & 114.0 & 4.1 \\
\hline Shrubs & & & & & 30.4 & & & & & 30.4 & 1.1 \\
\hline \multicolumn{12}{|l|}{ Short fallow } \\
\hline Other land Cover & 1.2 & & 8.8 & 0.8 & & & 532.8 & & & 543.6 & 19.4 \\
\hline Water & & & & & & & & 10.4 & & 10.4 & 0.4 \\
\hline Plantation & & & & & & & 0.8 & & 46.8 & 47.6 & 1.7 \\
\hline TOTAL '000 ha & 1092.8 & 41.6 & 756.8 & 184.4 & 45.6 & 0.0 & 615.2 & 10.4 & 49.6 & 2796.4 & \\
\hline Recent image $\%$ & 39.1 & 1.5 & 27.1 & 6.6 & 1.6 & 0.0 & 22.0 & 0.4 & 1.8 & & 100.0 \\
\hline
\end{tabular}

Source: FAO 1996 


\section{Field survey}

\subsection{Introduction}

Standard techniques exist for field surveys to estimate timber and fuelwood production but procedures are more limited for assessing most of the non-wood forest products (NWFP). These are of major importance for the local dwellers and the rural development, perhaps much more so than wood products e.g. Carter 1996, Salafsky et al. 1999. A survey of use of 90 tree species in the rural India showed all were used for wood, $30 \%$ for fruit, $20 \%$ for bark, $20 \%$ for gum and $12 \%$ for leaves (Chetty 1985). This survey shows that wood production is most important however, other products not included in the inquiry and environmental services have significant value for rural people. Production and extraction of NWFP may create more job opportunities, encourage local processing, increase employment opportunities and conserve traditional knowledge. Accordingly, inventory techniques need to be broadened to provide information on non-wood products.

Wood and non-wood products are closely associated with tree characteristics such as diameter, height, crown size, etc., so a good field inventory of trees will remain an important part of national agroforest inventories. Additionally, special studies to establish correlations between tree characteristics and selected non-wood products are required (see Section 7).

\subsection{Field measurements}

\section{Field forms}

Examples of field forms and field data collected in this phase are: (1) plot description form: for descriptive data relating to the sampling unit, e.g. location, site characteristics, ownership etc.; (2) plot enumeration form: for data on species and diameter class and sometimes tree-log information. Common data included are: species, diameter breast height overbark, saw log length, sawlog top diameter overbark; (3) sample tree data form: for height measurements on a subsampling basis to facilitate development of local volume equations. Common variables measured on the sample tree plots on a subsampling basis are: species, diameter breast height over bark, total height, crown projection, sawlog length, central diameter of each log overbark and/or underbark, and log lengths.

A sample field form used in village forest inventory of Bangladesh is given in Figure 3. 
Figure 3. Field form used in Bangladesh national inventory

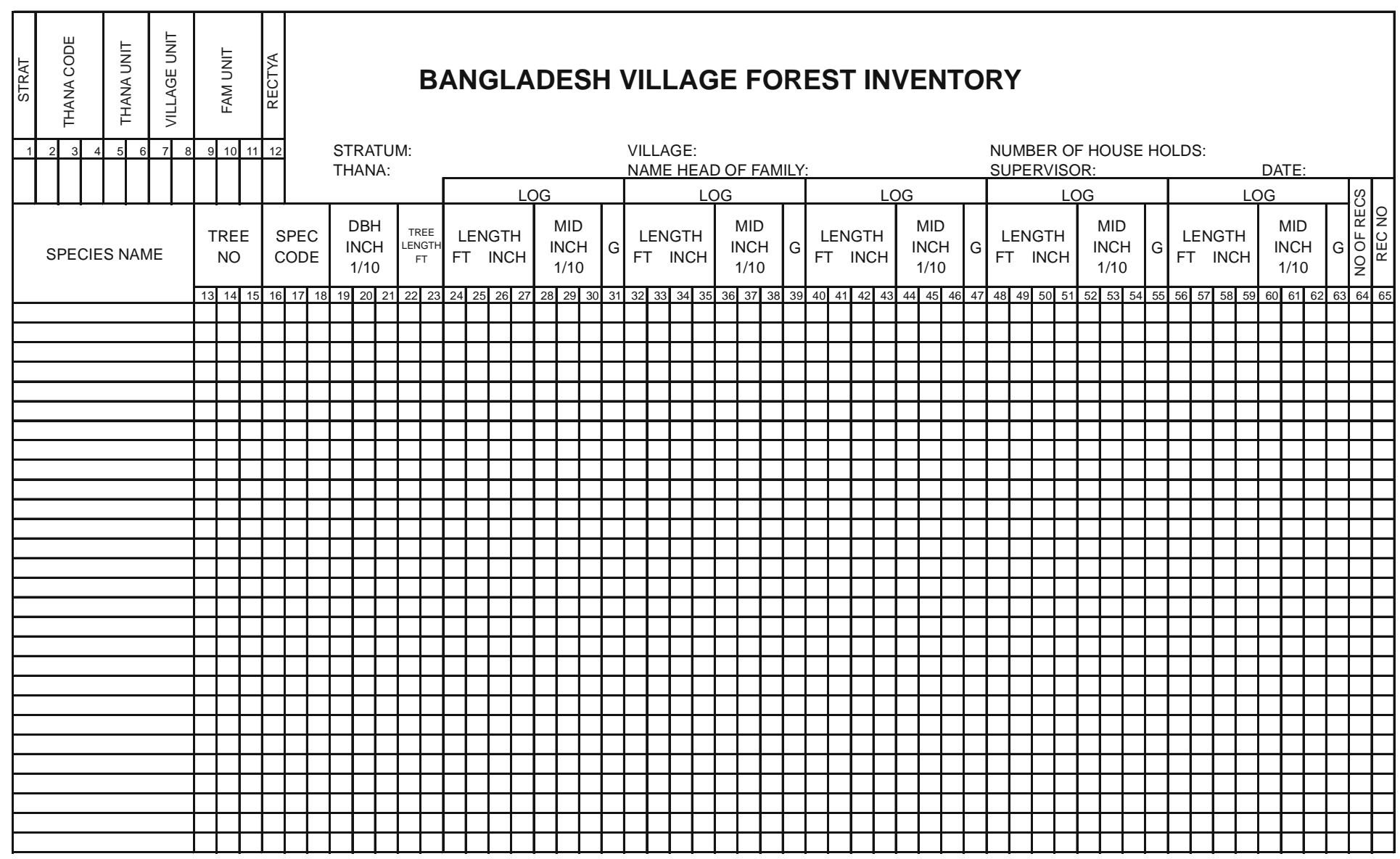


Some field forms are designed to facilitate data recording and its subsequent transfer to a digital medium with minimum error or time. Precoded field forms and code number manuals help in consistent data recording and entry. Modern handheld electronic data collectors can significantly improve the quality of field data since manual writing errors are avoided and validity and consistency tests can be made when the team is still on the plot. The portable computer can easily be interfaced with an ordinary PC using remote devices or direct transfer.

\section{Field manuals}

Field manuals are prepared to facilitate collection of field data. They provide definitions and detailed instructions for classifying the natural and cultural environment of sample plots and for measuring tree diameter and height. A manual also includes the coding system, description and use of measuring instruments and instruction on significant digits to be used for various fields.

\subsection{Maintaining quality control of fieldwork and data}

Errors in field measurements can be random or systematic. Systematic errors result in under or over estimation of means and also contribute to mean square errors; whereas random errors tend to decrease with increased sample size. Both types of errors deserve attention. Rules follow for minimising classification and measurements errors are:

- Define variables properly in the field manual to facilitate correct field measurements.

- Ensure variables can be objectively located.

- Define the entity to be classified or measured and the area unit.

- Clarify the processing/end use of data and its relevance.

- Limit the significant digits in classes/measurement.

- Ensure complete coverage of classes.

- Balance between classes.

- Reduce subjective influence.

- Train staff and control crew work.

- Edit field data in field and office; and

- Review completed field work.

\subsection{Consistency checking and data archiving}

During the field inventory, it is important to check field forms continuously and promptly for consistency and error. Both manual and computer checks should be 
made and feedback provided to the field staff. An appropriate data editing routine to check each item of the field form and any cross relations needs to be developed. Computer checking often detects errors not found by careful manual checks. The end product of the field survey should be clean and well-organised database. 


\section{Special studies}

\subsection{Introduction}

Special studies supplement sample survey work by providing additional information or developing functions for estimating variables which may require destructive sampling or are very costly to measure. An example is the estimation of volume of standing trees based on measurements, such as species, diameter and height, taken during the inventory. Studies may also be needed to estimate fruit or seed production, bark yield, fodder production from trees of variable diameter and/or height, or to estimate the weight of bamboo from size and/or length measurements etc.

Parameters which may require special studies in view of survey complexity during traditional forest inventory are:

Production (volume) of goods

1. Wood products

- Timber

- Fuel

2. Non-wood products

- Leaves/fodder

- Fruits/flowers

- Bark

- Gums/resin

- Grass/grazing

- Fauna

Production of services

1. Abiotic

- Windbreak/shelterbelt

- Shade

- Soil/water conservation

2. Biotic

- Carbon sequestration

- Biological diversity

- Aesthetic effect

There are no accepted procedures for national assessment of most non-timber forest products. More research on achieving a production-consumption balance of these products is needed in developing countries. 


\subsection{Tree volume estimation}

Common volume functions in forestry literature are:

$$
\begin{aligned}
& \mathrm{V}+\mathrm{a}+\mathrm{bD}^{2} \mathrm{H} \\
& \mathrm{V}=\mathrm{a}+\mathrm{bD}+\mathrm{c} \mathrm{D}^{2}
\end{aligned}
$$

where $\mathrm{V}$ is the volume, $\mathrm{D}$ the diameter and $\mathrm{H}$ the height; $\mathrm{a}, \mathrm{b}$, and $\mathrm{c}$ are the regression coefficients for a given species. Equations involving both diameter and height are called 'general volume equations' as they are applicable for the entire range of a species' distribution; whereas equations involving only diameter are called 'local volume equations' and are applicable to one site class only.

Planning and implementation of special studies follows a similar method to that for the sample survey, namely, design, data collection and data processing phases. Careful planning of design is important because the related fieldwork is usually more costly and may involve destructive sampling (felling, cross-cutting and volume measurements). Often it is not possible to fell enough trees to meet statistical demands. A compromise may be to restrict the special study to trees being felled by the local community although this may not cover the full range of sizes. In such a case, standing trees may be measured. Auxiliary data closely related to volume, e.g. tree diameter may be collected during the sample survey work to minimise possible bias. Tree height measurements are more time consuming than tree diameters, so measurements may be made on a subsample basis only. This hierarchic arrangement provides:

1. Felled tree data, including volume, height, diameter and species, collected during a special study;

2. Data, including height, diameter and species collected, on a subsample basis; and

3. Data, including diameter and species, collected on all sampled trees.

Trees selected for felling should be well distributed and cover all ecological zones where the species occurs. The number of trees to be felled may be determined from earlier experience or by statistical procedure with reference to the cost of collecting volume data, the variance of volume for a given species, and height and diameter measurements.

The manuals needed for special studies should cover: felled tree data collection, code numbers and felled tree data control.

The data collection on a subsampling basis is made at the same time as the main forest inventory. For example, Bangladesh Village Forest Inventory included the following sample tree measurements: species, diameter, total height, crown projection, crown freedom and sawlog length. The felled tree data included 
measurements of log cross sections to $10 \mathrm{~cm}$ diameter over bark including the mid diameter of the log over and under bark and volume of branches (by water displacement method).

The equations used in this Bangladesh inventory were:

$$
\begin{aligned}
& V=-6.91+0.18 D^{2} \text { jackfruit } \\
& V=-11.07+0.26 D^{2} \text { mango; and } \\
& V=-6.91+0.18 D^{2} \text { other tree species. }
\end{aligned}
$$

Where $\mathrm{V}$ is volume and $\mathrm{D}$ is diameter. Generally, diameter and height provide fairly good volume estimates and there are many regression formulas that can be applied. Height to the lowest live branch has been used as a form indicator but this is not very efficient. Measuring the diameter at a height of 5-6 $\mathrm{m}$ will provide a more precise estimate.

\subsection{Fodder yield study}

A study was made of fodder yield of two main species in Dun Valley of India (Chaturvedi 1985). Observations were made on 70 trees distributed in all diameter classes of Terminalia tomentosa and Anogeissus latifolia. Each tree was measured for total height, girth and crown diameter before lopping; fresh weight of the total leaf fodder yield; and fresh weight of the twigs and branches associated with the leaf fodder. The lopping was done according to local community practice. Five samples of green branches were measured in the field, and after air-drying, in the laboratory.

Nine regression equations were tried to establish the green fodder yield and fuel wood in the form of twigs and branches. The equation, which gave the best fit was:

$$
(\mathrm{Y})=\mathrm{a}+\mathrm{b}(\mathrm{G})+\mathrm{c}(\mathrm{H})
$$

where $\mathrm{Y}$ is the fodder/fuel yield, $\mathrm{G}$ tree girth and $\mathrm{H}$ tree height; $\mathrm{a}, \mathrm{b}$, and c are regression coefficients.

\subsection{Fruit yield}

Researchers in horticulture have made investigations on fruit yields and Shankar et al. (1996) have reported on a forest species, Emblica officinalis (Amla) in India, giving a fruit yield closely related to tree diameter. As it has been found that only a small fraction of the total production may actually be used, it is important to find methods to assess current harvesting levels. 


\subsection{Tree increment}

Tree growth and yield studies outside forests must take account the agricultural environment surrounding individual trees or groups of trees. Contributing factors are:

\section{Biotic factors}

- Agricultural crop.

- Tree species and age.

\section{Abiotic factors}

- Natural site factors (climate, soil, land form etc.).

- Man-made changes to the natural environment (soil working, irrigation, pesticides, fertilisation, etc.).

Tree growth can be influenced by the pattern of tree planting (single, in line and block), and interactions with agricultural components. Competition, symbiosis and climatic variability may be involved in these interactions. Standardisation (identification, classification and description) of site factors in agroforest systems is essential.

The system of permanent plots used for measurements in forests needs to be replaced in agroforests by a system of permanent trees with a complete documentation of site factors Mathematical functions such as Chapman-Richards may be found useful in agroforest conditions as they relate to organisms as well as populations.

\subsection{Participatory and rapid rural appraisal techniques}

\section{Outline of the methods}

Rapid Rural Appraisal (RRA) and Participatory Rural Appraisal (PRA) are systematic sequences of multi-disciplinary activities for producing accurate information and analysis of rural life, resource conditions and development needs, in an iterative and efficient manner. The techniques can be applied to make comprehensive assessments and analysis of rural life, including conditions and development needs. They assist in understanding rural systems, access local knowledge and assign people a central role in the survey process (Carter 1996). They involve local people directly in assessing their own resources; observe local conditions (fields, farms, homestead, etc.); and study existing information. 


\section{Guiding concepts and principles:}

- Multidisciplinary approach,

- Objective view, representative coverage, and cross-checking of conclusions (triangulation);

- Observation and record of facts;

- Ranking and sorting of issues;

- Exploration, discussions and formulation of solutions with full participation of the community.

A RRA/PRA team should have the linguistic capability to communicate with the local people. The team leader should be a local person (after necessary training) who is supported by a forester with good field experience in inventory. A simple field manual should be provided to guide data collection.

\section{Field experience related to assessment}

As a part of Joint Forest Management in India, a team of specialists under the initiative of the Society for Promotion of Wastelands Development (1992) prepared manuals on RRA giving useful information on conducting assessments and advice on the limitations of the collected data. RRA has proved effective in collecting information on forest products (particularly non-wood products), their volumes and flows, collection practices, and the community members involved. The data is mostly based on interviews, which may be prone to recall errors. Therefore, it is advisable to cross-check production estimates with knowledgeable people in the community including the local forester, village leaders, traders and school teachers. If time permits, stratified sample surveys with families from different social and economic background are recommended. These allow researchers to directly observe collections, photograph processes and measure the time requirements, volumes and weights.

The Society for Promotion of Wastelands Development manuals contain many examples of RRA and its limitations. They conclude: "while data collected through these methods are rough estimates, they can sketch a picture of the relative levels and patterns of different product flows, which, when combined with ecological data on stocking levels and productivity of different species, can lead to an assessment of sustainable harvesting and potential income levels'.

The Bangladesh Village Forest Inventory in concluded: 'Any questionnaire data is of limited reliability and should be avoided. This is particularly so with estimates of past harvest where the villager suspects he may be penalised, e.g. by additional taxation, if he gives a correct (and high) answer. Also reliability of questionnaire data can very largely depend on the attitude and aptitude of the recorder.' 
These remarks show the need for caution in using these methods in a national forest or agroforest inventory. They must be well supervised e.g. by a trained forester, who can ensure consistency and quality in collected data. It is stressed that RRA and PRA have great potential to provide insights into the intricate relationship between people and forest (or trees) which is almost impossible to acquire from any national inventory. 


\section{Data processing}

\subsection{Introduction}

A national inventory contains a large volume of inter-connected data requiring the services of a specialised person for processing and reporting. Experience shows that consideration of data processing problems at the inception of a forest inventory saves effort later. Some guidance on the coding system and design of field forms is useful at this stage. Well-designed field forms facilitate data collection and processing. Survey leaders must be properly trained in completing the forms in the prescribed format. Training team members in the data processing is always beneficial to the project. During the inventory implementation phase, it is important that data forms are continuously checked for consistency and error and feedback provided to field staff.

\subsection{Data processing algorithms}

There are a number of options for the development of the data processing programmes: (1) use an existing code; (2) adapt it to meet the needs; or (3) develop a tailor-made programme. However, programme writing and its debugging is time consuming and expensive. Every programme has at least one error and some bugs are not detected until the end of the data processing phase. On the other hand, use of an existing programme often has inherent constraints. Adaptations call for careful study of the original programme, making changes and debugging. FAO's (generalised) Forest Inventory Data Processing System, FIDAPS, was written in FORTRAN, later modified to FORTRAN for PC which was then replaced by dbase, and recently rewritten to make it user-friendly. To conclude, a decision on the best course of action should be made on the advice of a good programmer. Most forest inventory institutions have $\mathrm{PC}$-adapted systems for data processing. It is important to highlight the crucial role of data processing in the various stages of forest inventory

\subsection{Computational phase in forest inventory}

Analysis and tabulations take little time when data have been thoroughly checked manually and edited electronically. For a large operation, it is useful to prepare a broad flowchart (Figure 4). 
Figure 4. Data processing flow chart used in many inventories in the tropics

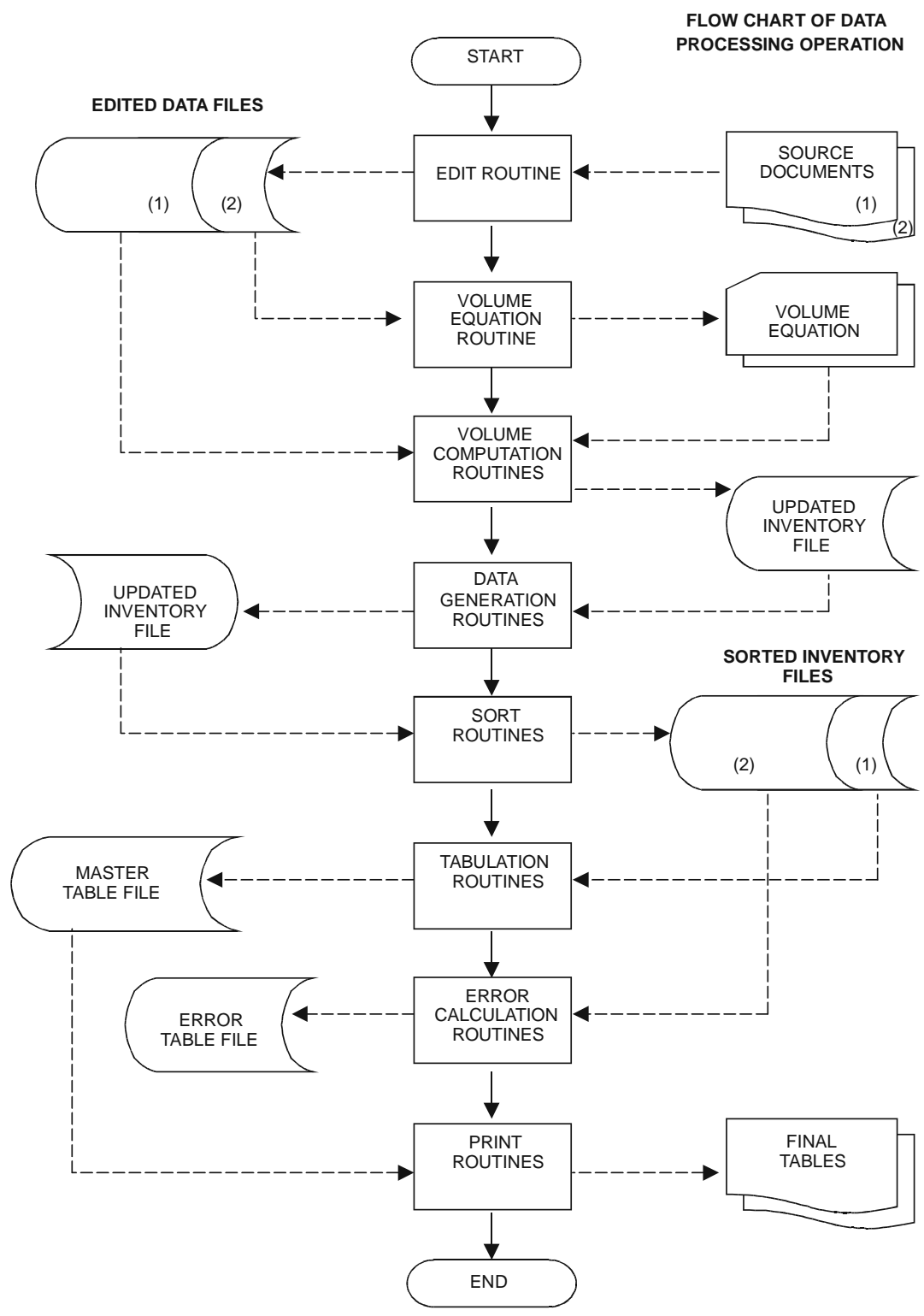


The major steps of calculation and programme development are:

I. Edit routine. This includes editing all field form data and checking for consistency.

II. Volume equation routine. This involves the following data processing steps:

1. Processing felled tree data including

a) Volume calculation of single trees by types of volume;

b) Scatter diagram of volume against diameter and height. The most used compound variable is $\mathrm{D}^{2} \mathrm{H}$.

c) Regression functions involving volume and a set of compound variables: $\mathrm{D}^{2} \mathrm{H}$ or $\mathrm{DH}$ etc. This step ends with the function:

$$
\mathrm{V}=\mathrm{f}(\mathrm{D}, \mathrm{H}, \text { Species })
$$

2. Processing sample tree data including measurements of height and diameter and species. The main steps are:

a) Editing of data;

b) Calculation of sample tree volume using the chosen general volume functions;

c) Scatter diagram of volume against diameter for the chosen functions; and

d) Local volume equation trials involving only volume and diameter of the sub-sampled trees. This step results in the function:

$$
V=f(D, \text { Species })
$$

which has only species and diameter as independent variables and can be used for calculating volume of all trees measured.

III. Processing of derived data and totals. This involves:

1. Processing of tree enumeration data by

a) Editing data and

b) Calculating enumerated tree volume for producing stand and stock tables.

2. Computating plot totals by species/diameter class for error calculations.

3. Processing of stand and stock tables by forest type.

4. Processing of area and growing stock tables. 
IV. Error calculation routine:

1. Calculation of sampling error based on plot totals

2. Special investigations, e.g. cutting calculations, area production models, etc.

3. Evaluation of survey design and data processing method

Print routines: this involves production of final output including tables, graphs, equations. The Bangladesh Village Forest Inventory, for example, included the following outputs:

Tree volume equations

Bamboo weight tables

Sawlog bark volume

Population data in sampled area

Total and per capita volumes - sample plots

Stock volume and stand tables

Log volume - match industry species

Bamboo resource table

Palm stand table

Areas of rattan (Calamus) and thatch grass

Standard error

Annual total volume harvest

Medicinal plants and uses

List of villages sampled

Conversion of measurement unit table

Map showing strata boundaries and selected sampling units.

\subsection{Database storage and archival routines}

Data collected during a forest inventory has a long-term value. The information extracted, to meet the immediate needs, constitutes a very insignificant use of information. The inventory data have wide application and constitute a permanent reference record. The data should be properly stored in digital media and welldocumented, including definitions, manuals used, measurement techniques and other relevant material. It should also be possible to rearrange data and create new outputs so that new information can be added and retrieved. 


\section{Survey evaluation}

\subsection{Introduction}

In this section, a review of the Bangladesh Village Forest lnventory is made to illustrate lessons useful for other inventories. The main thrust of this project was on inventory of the major and minor forest produce in village forests (Hammermaster 1981, Westerling 1981). This was carried out on a national basis and its results must be viewed in this context.

\subsection{Survey methodology}

This was the first inventory of village trees in Bangladesh. It focussed on wood and selected non-timber products useful to villagers. New techniques had to be developed to suit the inventory situation within certain cost and time constraints placed on the project. Conventional methods based on area could have been used, but would have been time consuming with difficult photo interpretation and mapping requirements.

It was assumed that there is a relationship between village forests and population density. Detailed population data at village level was available and so population rather than area was the basis of sampling design and implementation. The outcome of the inventory was the usual total volume and stand tables; and a special feature was the use of volume per capita rather than volume per unit area values.

These newly developed techniques, though considered adequate for the purpose, could be improved. In planning future similar village woodlot inventories consideration should be given to areas and places where improvement could be made and pitfalls avoided. These are discussed below.

A two-stage sampling design after stratification proved satisfactory. However, the first stage sampling of $10 \%$ (44 primary sampling units of a total of 440) was too low and could have led to 'bunching'. A minimum of $20 \%$ would have achieved a better primary sampling unit spread.

A smaller size and larger number of primary sampling units would have given a lower standard error when using ratio estimates, particularly at stratum level. In three of the six strata, the number of samples measured was small. Thus, when allowing for reduction due to degrees of freedom, a high value of student's ' $t$ ' at $95 \%$ had to be applied leading to a high standard error for these strata.

In this study, questionnaire data was of limited reliability and was avoided. This is particularly the case with estimates of past harvest where a villager suspects he may 
be penalised for a correct (high) answer. Also the reliability of questionnaire data may very largely depend on the attitude and aptitude of the recorder.

Volume table compilation was critical. Both total volume and merchantable (conversion log) volume was required but only a table for total volume was compiled. There should have been a way to adequately estimate both volumes through volume table application.

Measurable tree variables were examined. The crown projection as well as diameter may be important for such trees but it was realised that field staff could not easily and accurately measure crown projection. The project had data on crown projection for those trees studied for volume table compilation but this was not examined fully.

Rate of harvest and increment figures were required. A minimum number of permanent inventory plots should be established and periodic measurements organised. Harvest figures can be obtained over the short term (1-2 years), while meaningful increment data takes longer.

In such a wide ranging inventory survey, additional data on consumption should be collected if not by the same field party then by another team in the same sampling unit (i.e. village) on a compatible basis. This will reduce time and make such data consumption/resource directly comparable. Measurement definition and units should be the same for both sets of survey figures. In Bangladesh, consumption and inventory surveys were not coordinated at the planning stage with the result that two independent projects (under separate ministries) were formulated. Results from both were compared but it made correlation more difficult. Also, two separate surveys meant increased costs.

Decisions are required on computerisation prior to commencement of the field inventory and design of field sheets. Existing software (i.e. FIDAPS) should be examined to see if it is applicable to the data and compatible with existing computers. In the Bangladesh Inventory, it was not feasible to use FIDAPS without major amendments as the initial field sheet, and thus layout of collected data had not been meshed with FIDAPS. However, a tailor-made program was able to be devised and all data processed within a period of 6 weeks could be implemented.

\subsection{Development aspects of the village forest inventory}

Results of the inventory provided the first basic information on Bangladesh's important village forest resource. Follow up development studies can now build on this information to help solve the problems associated with the supply of fuelwood. Precise estimates of increment and removals are still required. In the long-term this 
will require permanent inventory plots but as an interim measure, increment borings will provide indicative data on growth.

A study of the social aspects of village forest management is required before making changes or introducing new techniques to upgrade productivity of the forest. It may be possible to make very limited plantings on rice field boundaries, irrigation tank embankments, grazing areas etc., but as most land is fully utilised, increased productivity can only be achieved by genetic improvements to existing species or introducing new species.

A review of options and strategies should precede formulation of an overall development plan for village forest areas. Additional capacity building of local staff in community forest survey and development needs to be included. 


\section{Acknowledgements}

My association with many inventory experts has enhanced this report. The longest cooperation has been with my Swedish friend and guru Nils-Erik Nilsson. My

former colleagues at Forest Survey of India were influential in my early career. The technical cooperation with Bertil Matérn at the Royal College of Forestry, Sweden and with Jean Paul Lanly, Klaus Janz and Bo Ranneby at FAO, Rome is very much appreciated. I particularly thank Eric Hammermaster, the Team Leader of the FAO Bangladesh Village Forest Inventory project. Finally I gratefully acknowledge the support and encouragement of my wife, Indira. 


\section{References}

Carter, J. (ed.) 1996 Recent approaches to participatory forest resource assessment. Rural Development Forestry Study Guide 2. ODI, London, UK.

Chaturvedi, A.N. 1985 Fuelwood and leaf fodder yield. Unpublished report. Tata Energy Research Institute, India.

Chetty, R.N.V. 1985 Social forestry and forest based industry. Indian Forester Volume 111 Number 9 (Sept 1985 issue), 678-692. Dehra Dun, India.

Cochran, W.G. 1965 Sampling techniques. John Wiley and Sons, New York.

FAO 1980 Forest Resources Appraisals in Forestry and Land Use Planning. Report of FAO/SIDA/GOI Seminar held in Dehra Dun/Delhi, India in 1978, FAO, Rome.

FAO 1984 Land evaluation for forestry, Forestry paper 48. FAO, Rome.

FAO 1995 Forest resources assessment 1990: Global synthesis, forestry paper 124. FAO, Rome.

FAO 1996 Survey of tropical forest cover and study of change processes, forestry paper 135. FAO, Rome.

Forest Survey of India 1995 Inventory survey of Gurgaon district, Haryana State, inventory results, FSI, GOI, Dehra Dun. UP, India.

Forestry Commission 1990 Design of census of woodlands and trees 1989-92, Forestry Commission, Edinburgh. Scotland, UK.

Forestry Faculty of IPB 1986 Report of the study on fuelwood potential and supply in the west province of Java, Forestry Faculty Fuelwood Study Team of Bogor Agricultural University (IPB). Bogor, Indonesia.

Hammermaster, E. 1981 Inventory results. Unpublished report. UNDP/FAO Project BGD/78/029, Village Forest Inventory. FAO, Rome.

Islam, M. N. 1983 Evaluating the impact of using agricultural residues for fuel as a substitute to insufficient fuelwood supply. Technical Report to FAO. Rome.

Janz, K. 1978 Types of problems to be tackled by forest inventories. Unpublished report. Lectures on forest inventory at FIPI, Hanoi, Vietnam.

Matérn, B. 1984 Four lectures on forest biometry, mimeographed lecture notes, Swedish University of Agricultural Sciences. Umeo, Sweden.

Nichols, J., Sharp, J., Titus, S., Orme, W., and Gialdini, M. 1975 Cost-effectiveness comparison of existing and Landsat based total timber resources inventory system, a research paper, University of Berkeley. California, USA.

Nilsson, N-E. 1974 Forest inventory problem formulation, FAO/SIDA Training course in forest inventory, FAO/SWE/TF 125 Report, FAO. Rome. 
Nilsson, N-E. 1978 A Framework for forest resources development planning and forest resources appraisal. The paper is included in full in the earlier citation FAO 1980, Forest Resources Appraisals in Forestry and Land Use Planning.

Obaidullah, M. 1980 Sampling design and statistical analysis considerations for national village inventory of Bangladesh. Unpublished report. UNDP/FAO Project BGD/78/029, Village Forest Inventory. FAO, Rome.

Ranneby, B. 1985 Designing a new national forest survey for the Heilongjiang Province. Unpublished report. Project CPR/82/010, FAO. Rome.

Salafsky, N., Cordes, B., Parks, J. and Hochman, C. 1999 Evaluating linkages between business, the environment, and local communities: Final analytical results from the Biodiversity Conservation Network, Biodiversity Support Program. Washington, D.C.

Sandewall, M. and Nilsson, N-E. Forthcoming. The Area Production Model (APM) - a tool and concept for sustainable land-use and forest resource management, a manuscript submitted for publication in the Journal of Environment and Management.

Shankar, U., Murali, K.S., Shanker, U.R., Ganeshaiah, K.N. and Bawa, K.S. 1996 Extraction of non-timber forest products in the forests of Biligiri Rangan Hills, India. 3. productivity, extraction and prospects of sustainable harvest of Amla Phyllanthus emblica (Euphorbeaceae). Economic Botany 50: 270-279.

Singh, K.D. 1982 A critical evaluation of the cost-effectiveness of aerial photo interpretation techniques to forest resources survey. Training Course on application of new remote sensing techniques to forest resources survey, People's Republic of China, 28 April to 24 May 1980. Unpublished report. Project CPR/82/010, FAO. Rome.

Singh, K.D. 1986 Conceptual framework for the selection of appropriate Remote Sensing Techniques. In Practical Application of Remote Sensing in Forestry. p.14, published by Kluwer Academic Publishers, Dordrecht, the Netherlands.

Singh, K.D. 1987 Remote sensing in village forestry: Lecture notes for the training course in Feldafing, Germany, Mimeographed lecture notes.

Singh, K.D. and Nilsson, N-E. 1974 On the problem of identification and evaluation of the environmental functions of forests, Royal College of Forestry, Sweden. A paper presented at FAO/ECE Meeting of Experts on Environmental Functions of Forests, FAO/ECE Geneva.

Smith, S. Mc Farlane and Phillips J. 1992 Line transect sampling in discontinuous tropical vegetation, a technical report under a Canadian International Development Authority Project. Unpublished report. Andhra Pradesh Forest Department, Hyderabad. India.

Society for Promotion of Wastelands Development 1992 Field methods manual. Volume I: Diagnostic Tools for Supporting Joint Forest Management 
Systems \& Volume II: Community Forest Economy and Use Patterns: Participatory Rural Appraisal Methods in South Gujarat, India, edited by Mark Pfoffenberger, Besty McGean, Arvind Khare and Jeff Campbell and published by Society for Promotion of Wastelands Development, New Delhi, India.

Thompson, S.K. 1992. Sampling. John Wiley and Sons, New York.

Westerling, S. 1981 Data processing. Unpublished report. UNDP/FAO Project BGD/78/029, Village Forest Inventory. FAO, Rome. 


\section{Annex 1. Emerging technologies}

\section{Introduction}

This annex gives a short account of recent technological developments such as geopositioning systems (GPS), geographic information system (GIS) and modeling, which can be used with advantage in national forest and agroforest inventories. These technologies in no way diminish the importance of accurate field work or good interpretation of images. They will reduce the cost and/or duration of inventories and, most importantly, enhance analytical capacity.

\section{Geo-positioning systems}

The GPS is a satellite-based navigation system, which can be used for determining the coordinates $(x-y-z)$ of any observation point within a few metres and enables rapid mapping of points, lines and areas. The accuracy depends on the equipment, field conditions, especially canopy cover, and the procedure used. Combined with survey maps such systems can replace the traditional method of locating field plots with maps, chain and compass. The cost of the inventory can be reduced significantly as operations such as like line clearing, are no longer required. GPS permits fast, accurate and inexpensive plot location.

Small, cheaper and more flexible GPS models are becoming available. Hand-held models which allow collection and maintenance of spatial data for GIS use are ideal for mapping and managing spatial data for natural resource mapping, environmental studies, etc. Customised attributes of information can be recorded and this field data can be incorporated seamlessly into GIS.

\section{Geographic information system}

The term 'GIS' is used in two ways. It can refer to computer hardware and software for handling geographic information or more broadly to all GIS equipment and operations, including the hardware, software, input data, editing and storing, data processing and reporting (Figure 5).

The application of GIS to complex problems e.g., land use and environmental planning, resources management, integrated area development, etc., has been important for a long time. However, recent advances in computer technology e.g., database management systems, computer-assisted drafting and mapping, and modeling techniques have made GIS a powerful and affordable tool. Using relatively inexpensive personal computer, it is now possible to input, integrate and 
store information in the form of data and maps, to analyse and manipulate data, to apply complex modeling algorithms and display results as graphs, maps or tables. GIS input data must be well prepared to minimise costs., Total planning is required to use a GIS efficiently, starting with survey and analysis of user's output requirements, then input design, reliable and relevant data collection and modeling.

Figure 5. Overview of a geographic information system

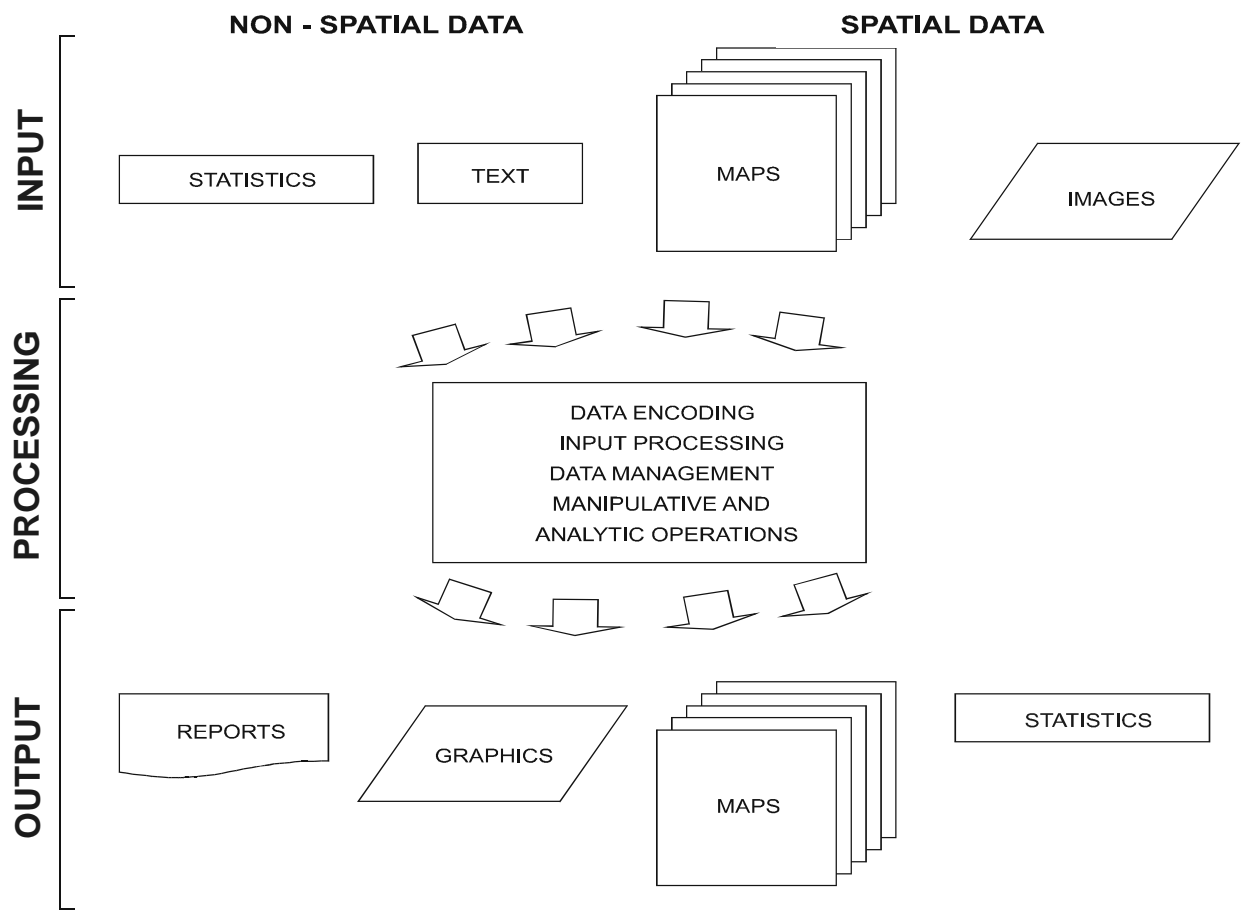

\section{Modeling}

Models are used to study the interaction among various components, dynamics behaviour of the entity or changes under alternative assumptions. Models are subjective as they include only a subset of associated observations or measurements relevant to a problem. A good model excludes unrelated details and focuses on fundamental aspects of the reality under study.

As models are used in many contexts, it is difficult to define even broad types of usage without ambiguity. One major division is between descriptive and normative 
(predictive) models. The former is concerned with description of the real world, such as a scale model, map, a series of equations and other analogues; the latter, an ideal type, is what might be expected to occur in the real world under certain conditions. Models have also been classified as static (steady state) or dynamic according to their changing nature; deterministic and stochastic according to degree of probability associated with their prediction; or holistic and reductionistic according to the level of detail included in the model.

In complex modeling, a start is made with establishment and testing of descriptive models to determine causal relationships between various variables. Once causal relationships are known, it is possible to develop a hypothesis, theory, or model, which can predict outcomes given similar circumstances in another area. Wellestablished relationships can make for very powerful normative models essential for proactive land management.

The Area Production Model will be described to illustrate the use of modeling. This model was originally developed for a World Bank investment study in India about 1980 and has now been significantly improved (Sandewall and Nilsson, forthcoming). It aims to simulate developments of land use and primary area production. It can be used in connection with production and consumption studies at the level of civil districts, communes or similar.

The model run will be illustrated to analyse the impact of alternative policy decisions on fuelwood production and consumption in the Adilabad district in Andhra Pradesh (India). This district has a forest cover of 40\%. Four scenarios are studied using forest resource and socioeconomic data. Efforts were made to make the model as realistic as possible. The alternative scenarios and underlying assumptions are given in Table 6. 
Table 6. Assumptions made in the model regarding future state of the district

\begin{tabular}{|c|c|c|}
\hline Scenario & Supply-side assumptions & Demand-side assumptions \\
\hline 1 & No change & No change \\
\hline 2 & $\begin{array}{l}\text { Improvement of wood production } \\
\text { on agricultural land; and } \\
\text { establishment of } 100000 \text { ha of } \\
\text { fuelwood plantations }\end{array}$ & No change \\
\hline 3 & No change & $\begin{array}{l}\text { Reduction of population growth } \\
\text { rate; and reduction of } 2 \% \text { per } \\
\text { year of biomass demand per } \\
\text { capita }\end{array}$ \\
\hline 4 & $\begin{array}{l}\text { Improvement of wood production } \\
\text { on agricultural land; and } \\
\text { establishment of } 100000 \text { ha of } \\
\text { fuelwood plantations }\end{array}$ & $\begin{array}{l}\text { Reduction of population growth } \\
\text { rate; and reduction of } 2 \% \text { per } \\
\text { year of biomass demand per } \\
\text { capita }\end{array}$ \\
\hline
\end{tabular}

The study concluded: (1) a long term programme (25 years or more) is essential to balance supply with demand; (2) increased production and controlled consumption are necessary. which suggests intersectoral integration in the local development planning will be needed; (3) the forest plantations must be high yielding to achieve self-reliance in the shortest time; (4) development of plantations must be with people participation. Grazing and illicit wood removal must be controlled; (5) adequate finance on a long-term basis must be secured. 


\section{Annex 2. Institutional requirements}

\section{Introduction}

Planning a national inventory of village forests is an intellectually demanding task. It requires expertise in many aspects of a rapidly growing science. Nevertheless, forest inventory implementation is essentially a practical activity where trees have to be correctly identified and measured, records of production and consumption maintained and a data archive established. Even in traditional forest inventory, local people often identify rain forest species. So a successful forest inventory requires a good mix of theoretical and practical knowledge. Institutional requirements are described in the different phases of the inventory.

\section{Planning phase}

National forest inventory planning requires an intellectual oversight, strong leadership, continuity of the institution and continuous updating of knowledge. A national-scale inventory needs sampling procedures combined with technology such as remote sensing for stratification, GPS for location and personal computers for data processing. This technology is necessary to reduce costs, enhance capacity for collecting, processing and analysing data, and interpreting results. A good knowledge of spatial variability, personnel management and an excellent knowledge of statistics is needed to make a practical design. A common set of definitions and a classification system must be developed, quality control of all data exercised and staff training provided.

\section{Implementation phase}

Many activities in a village forest inventory can be decentralised and implemented using the local people and knowledge e.g., species identification and tree measurements tropical forest inventories. Local people can also be heavily involved in production and consumption studies, and recording new plantings and natural regeneration. This is a cost-effective approach.

A village can be used as the sampling unit (see Section 3). This is efficient for sampling and local people can observe and record changes in the village landscape as and when they occur. The same is true for recording new plantings and natural regeneration, mortality and harvest. Many special studies, as described in Section 7, such as measurements of non-wood forest products, can be carried out by local people after training and with written guidelines in the local language. 


\section{End phase}

The end phase is the analytical and follow-up phase. An inventory is not an end in itself but only a component of a larger decision making process and has only an academic value if not followed by policy analysis, development planning and follow-up action.

The increasing importance of village forests for timber, fuel, fodder, environmental conservation and aesthetic purposes has been emphasised. Further opportunities for afforestation and forest rehabilitation in developing countries are very high due to availability of a significant area of deforested and degraded lands. The new forests can be established on the basis of information from a national inventory and policy analysis to interpret the information, plan and recommend follow-up action. Generally, the country's capacity needs to be strengthened to perform these important tasks. 

(C) 2000 by Center for International Forestry Research

All rights reserved. Published in December 2000

Printed by SMT Grafika Desa Putera, Indonesia

Cover ilustration by Indira Singh

ISBN 979-8764-55-2

\section{Published by}

Center for International Forestry Research (CIFOR)

Bogor, Indonesia

P.O. Box 6596 JKPWB, Jakarta 10065, Indonesia

Tel: +62 (251) 622622; Fax: +62 (251) 622100

E-mail: cifor@cgiar.org; Website: http://www.cifor.cgiar.org

with support from

International Fund for Agricultural Development (IFAD)

107, Via del Serafico, Rome 00142 - Italy

Tel: +(39) (06) 54591; Fax: +(39) (06) 5043463

E-mail: ifad@ifad.org; Website: http://www.ifad.org 

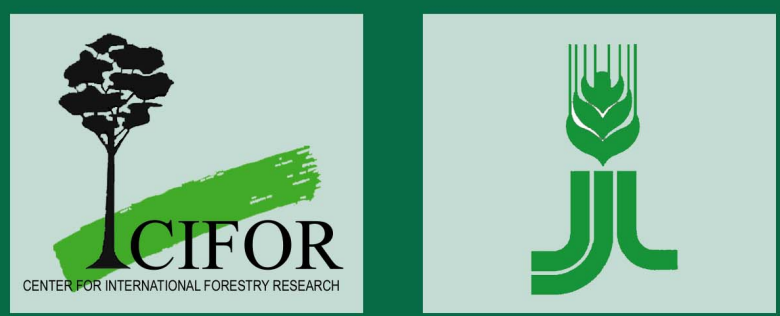

ISBN 979-8764-55-2 